\title{
All-carbon [3 + 2] cycloaddition in natural product synthesis
}

\author{
Zhuo Wang ${ }^{* 1}$ and Junyang Liu ${ }^{2}$
}

\author{
Review \\ Address: \\ ${ }^{1}$ School of Medicine, Southern University of Science and Technology, \\ Shenzhen, 518055, People's Republic of China and ${ }^{2}$ Academy for \\ Advanced Interdisciplinary Studies, Southern University of Science \\ and Technology, Shenzhen, 518055, People's Republic of China \\ Email: \\ Zhuo Wang ${ }^{*}$ - wangz3@sustech.edu.cn \\ * Corresponding author \\ Keywords: \\ all-carbon; cyclization; [3 + 2] cycloaddition; natural product synthesis;
} stereocenters

\author{
Beilstein J. Org. Chem. 2020, 16, 3015-3031. \\ https://doi.org/10.3762/bjoc.16.251 \\ Received: 25 August 2020 \\ Accepted: 21 November 2020 \\ Published: 09 December 2020 \\ Associate Editor: D. Y.-K. Chen \\ (C) 2020 Wang and Liu; licensee Beilstein-Institut. \\ License and terms: see end of document.
}

\begin{abstract}
Many natural products possess interesting medicinal properties that arise from their intriguing chemical structures. The highlysubstituted carbocycle is one of the most common structural features in many structurally complicated natural products. However, the construction of highly-substituted, stereo-congested, five-membered carbocycles containing all-carbon quaternary center(s) is, at present, a distinct challenge in modern synthetic chemistry, which can be accessed through the all-carbon [3 + 2] cycloaddition. More importantly, the all-carbon [3 + 2] cycloaddition can forge vicinal all-carbon quaternary centers in a single step and has been demonstrated in the synthesis of complex natural products. In this review, we present the development of all-carbon [3+2] cycloadditions and illustrate their application in natural product synthesis reported in the last decade covering 2011-2020 (inclusive).
\end{abstract}

\section{Introduction}

The highly-substituted, stereo-congested, five-membered carbocycle containing contiguous stereocenters is one of the most common structural features in many structurally complicated, biologically important natural products [1-7] (Figure 1). Meanwhile, the construction of quaternary carbon stereocenter(s) is, at present, a distinct challenge in modern synthetic chemistry [8-11]. Therefore, the synthesis of highly-substituted five-membered carbocycles bearing congested arrays of stereocenters within the polycyclic framework of complex natural products usually require a sophisticated synthetic planning. This issue is not trivial because only a few strategies are available for the efficient synthesis of such an intriguing molecular architecture. More importantly, the all-carbon [3 + 2] cycloaddition can forge vicinal all-carbon quaternary centers [12] in a single-step operation and provides a direct access to various substituted fivemembered carbocycles. These characteristics make the all-carbon [3 + 2] cycloaddition an appealing method and/or strategy in the synthesis of complex natural products (Figure 2).

The 1,3-dipolar cycloaddition has been well-documented and widely used for the construction of five-membered heterocycles since the 1960s [13]. However, the development of the 


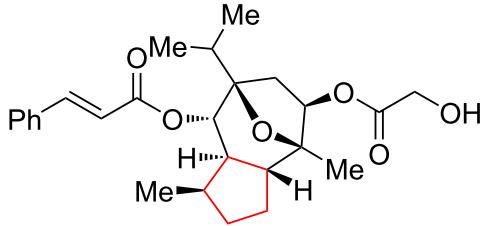

(-)-englerin A (1) anticancer

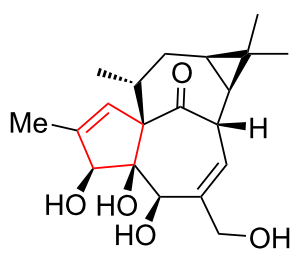

ingenol (4)

anticancer

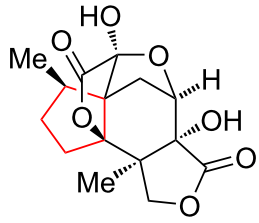

(-)-jiadifenolide (2) neurotrophic

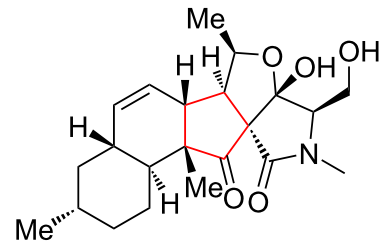

(-)-fusarisetin A (3) anticancer

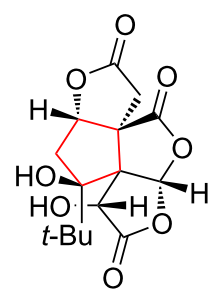

bilobalide (5) neuroprotective

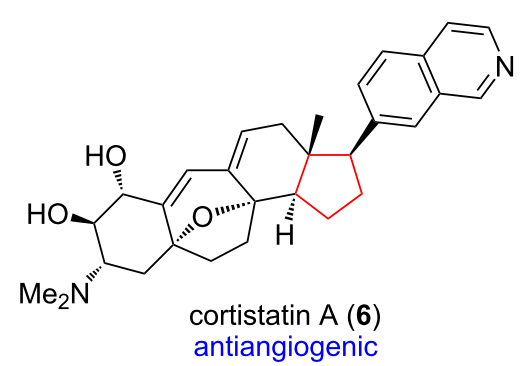

Figure 1: Highly-substituted five-membered carbocycle in biologically significant natural products.

A)

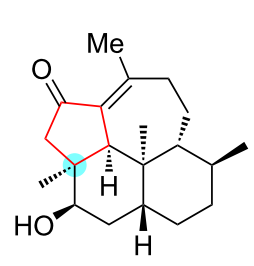

3ß-hydroxykemp-7(8)-en6-one (7)

Paquatte [23]

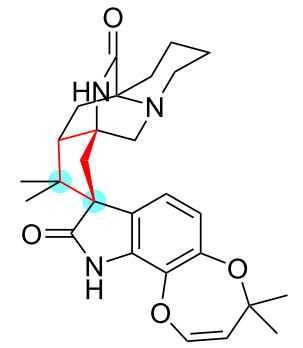

marcfortine B (8)

Trost $[38,39]$

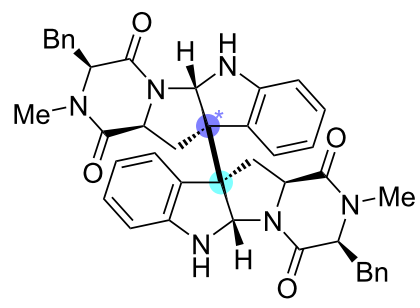

(-)-ditryptophenaline (12) Lu [46]<smiles>Cc1ccc(C2(C)CCCC2(C)C)cc1</smiles>

(+/-)-cuparene (13) Winne [69]

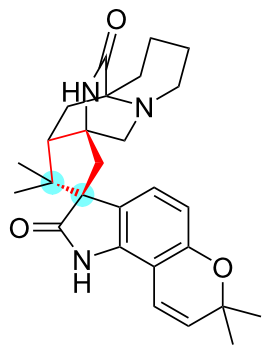

marcfortine C (9)

Trost [39]

B)
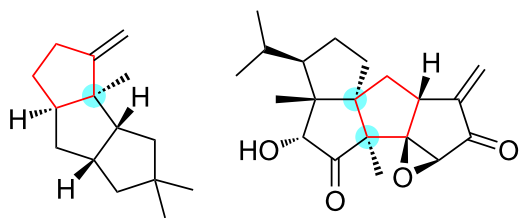

(+/-)-hirsutene (14) (-)-crinipellin A (15) Lee [30]

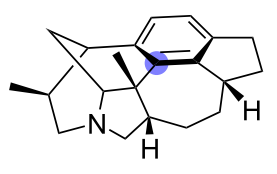

daphenylline (11)

Li [42];

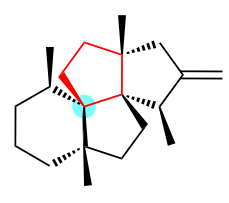

waihoensene (16) Lee [31]

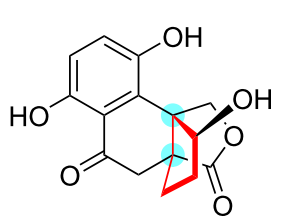

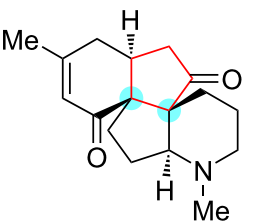

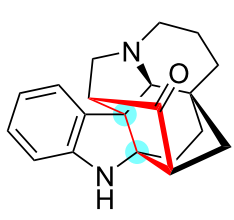

(-)-lingzhiol (17) lycojaponicumin C (18) kopsanone (19) Yang [49] Yang [58] Ye [67]<smiles>O=C(CC12CCC3O[C@H]4CCC(=O)N4C(O)C31CCOC2=O)c1cc(O)ccc1O</smiles>

sinensilactam A (20) Yang [59]<smiles>CC1(C)CCC[C@]2(C)[C@H]3CC[C@H](CO)C[C@]34CC[C@]12C4</smiles>

phyllocladanol (21)

Wang [68]

Figure 2: Natural product synthesis featuring the all-carbon [3 + 2] cycloaddition. (Quaternary carbon center(s) created by all-carbon [3 + 2] cyclization are highlighted in cyan; quaternary carbon center(s) created that are removed by subsequent transformations are highlighted in lilac; cyclopentane structures forged by the all-carbon [3 + 2] cyclization are labeled in red). (A) The intermolecular all-carbon [3+2] cyclization features as the key reaction. (B) The intramolecular all-carbon [3 + 2] cycloaddition features as the key reaction. 
all-carbon [3+2] cycloaddition, for instance, Berson's and Little's [3 + 2] cycloaddition through diyl trapping with an olefin $[14,15]$ and Trost's palladium-catalyzed trimethylenemethane cycloaddition [16], which allows the preparation of five-membered carbocycles, have been emerged since the 1970s. Thereafter, many novel and important all-carbon [3 + 2] cycloaddition reactions, such as the phosphine-catalyzed [3+2] cycloaddition [17], platinum-catalyzed [3 +2 ] cycloaddition [18], and Rhodium-catalyzed [3 +2 ] cycloaddition [12], were invented and have been extensively used in natural product synthesis in the last decade. Many reviews focusing the method development of the all-carbon [3 + 2] cycloaddition have been published [19-21]. However, there is no review effort, to the best of our knowledge, has been paid attention to the development of the all-carbon [3+2] cycloaddition with an emphasis on the natural product synthesis. Therefore, we are motivated to provide a timely and focused review of all-carbon [3+2] cycloadditions in natural product synthesis.
In this review, we present the development of the all-carbon $[3+2]$ cycloaddition and discuss its application in natural product synthesis reported from 2011-2020. We begin with describing the brief history of the all-carbon $[3+2]$ cycloaddition with selected natural product syntheses reported before 2011 [22-26]. Next, we discuss the synthetic methods including the proposed mechanism and/or catalytic cycle and focus on illustrative examples of natural product syntheses. Moreover, several natural product syntheses featuring all-carbon [3+2] annulation are elaborated. Lastly, we discuss future directions and opportunities for the all-carbon $[3+2]$ cycloaddition.

\section{Review}

In 1981, Little and co-workers utilized a trimethylenemethane (TMM) cycloaddition as the key reaction to synthesize the tricyclic compound $\mathbf{2 5}$, which led to the synthesis of ( \pm )-hirsutene (14) [22] (Scheme 1A). Refluxing azo compound $\mathbf{2 2}$ in acetonitrile generated the proposed biradical intermediate

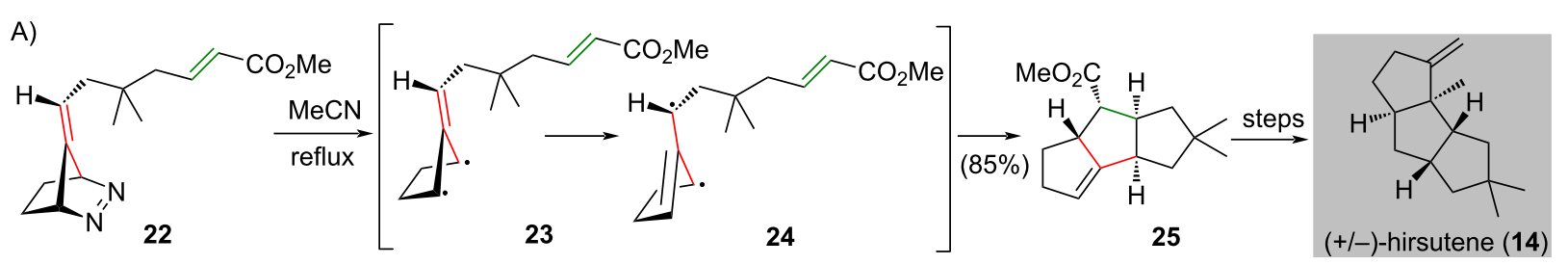

B)

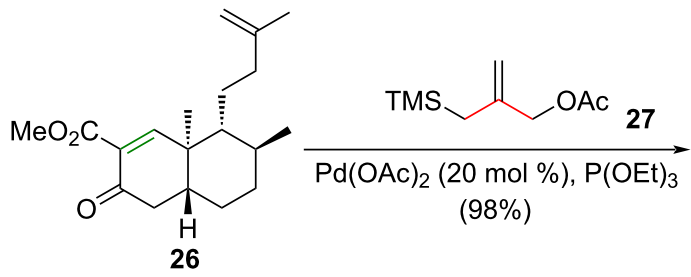

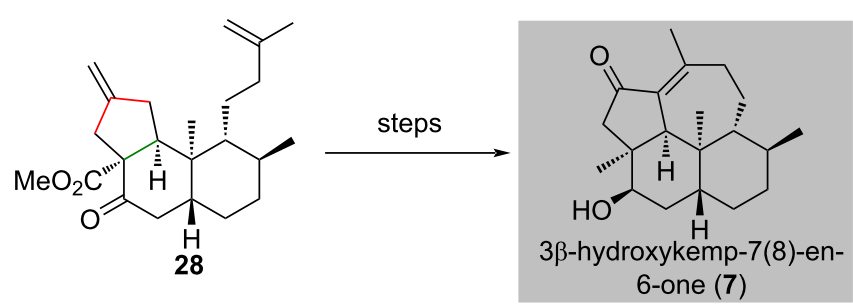

C)

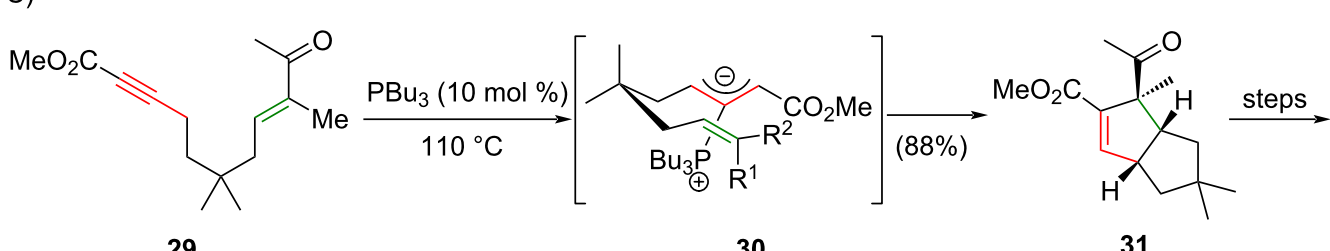

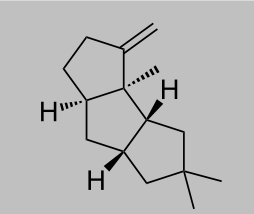

D)<smiles>C=CCC(C)(C)C/C=C\CCC1(/C=N\N2CC2C)CO1</smiles>
32<smiles>C=CCC(C)(C)C=C1CCCCC1</smiles>

30

Scheme 1: Representative natural product syntheses that feature the all-carbon [3 + 2] cyclization as the key reaction, reported before 2011. (A) TMM cycloaddition of diyl $\mathbf{2 4}$ resulted from dinitrogen extrusion/isomerization is used to prepare tricycle $\mathbf{2 5}$, which is a synthetic precursor of ( \pm )-hirsutene (14) [22]. (B) Synthesis of 3ß-hydroxykemp-7(8)-en-6-one (7) features a palladium-catalyzed intermolecular [3 +2 ] cycloaddition to generate tricycle 28 [23]. (C) A stereospecific phosphine-catalyzed [3 + 2] cycloaddition completes the synthesis of ( \pm )-hirsutene (14) [25]. (D) Linear alkylidene carbenes involved TMM [3 + 2] cycloaddition produces tricycle 36 in the preparation of $( \pm)$-hirsutene (14) [24]. 
23 through nitrogen extrusion. This intermediate underwent isomerization to $\mathbf{2 4}$ and intramolecular diyl trapping through a $[3+2]$ cycloaddition to give fused tricycle 25 in $85 \%$ yield. The

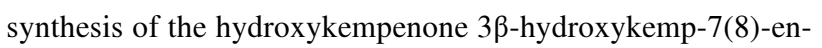
6-one (7) features Trost's palladium-catalyzed trimethylenemethane [3 + 2] cycloaddition [27] and was reported by Paquette and co-workers in 1992 [23] (Scheme 1B). Catalytic TMM [3 + 2] cycloaddition of activated octalone $\mathbf{2 6}$ and the trimethylenemethane precursor 27 selectively produced adduct $\mathbf{2 8}$ in $98 \%$ yield, which is a synthetic precursor of $3 \beta$-hydroxykemp-7(8)-en-6-one (7).

Another two syntheses of ( \pm )-hirsutene (14), after Little's pioneering work [22], were accomplished by Krische [25] and Lee [24] independently in 2003. (Scheme 1C and Scheme 1D) In Krische's synthesis, a stereospecific intramolecular phosphine-catalyzed [3 +2$]$ cycloaddition of 2-butynoate with electron-deficient alkene $\mathbf{2 9}$ afforded cycloadduct $\mathbf{3 1}$ in $88 \%$ yield as a single diastereomer [25] (Scheme 1C). Later, Lee`s synthesis of $( \pm$ )-hirsutene (14) used an alkylidene carbene as source of TMM diyl in the intramolecular [3 + 2] cycloaddition [24] (Scheme 1D). Heating of epoxyaziridinyl imine 32 produced tricyclic compound $\mathbf{3 6}$ in $57 \%$ yield as a single product. The authors proposed that heating of epoxyaziridinyl imine $\mathbf{3 2}$ generates alkylidene carbene $\mathbf{3 3}$. Transformation of $\mathbf{3 3}$ to TMM diyl 35 enables an intramolecular [ $3+2]$ cycloaddition to give the desired tricyclic product $\mathbf{3 6}$.

\section{Trimethylenemethane (TMM) cycloaddition}

An intramolecular trimethylenemethane diyl [3 + 2] cycloaddition was reported by Berson [28] and Little [14] independently in the late 1970s, which was used to prepare ( \pm )-hirsutene (14) in 1981 [22] (Scheme 1A). In 2003, Lee and co-workers disclosed an intramolecular trimethylenemethane diyl [3+2] cycloaddition with a linear alkylidene carbene as diyl source and was applied in the synthesis of linearly fused triquinane ( \pm )-hirsutene (14) [24] (Scheme 1D). In 2011, the same research group used allenyl diazo compound $\mathbf{3 8}$, which was generated from the reaction between aldehyde $\mathbf{3 7}$ and $p$-toluenesulfonehydrazide in the presence of sodium hydride upon heating, to produce diyl 40 [29] (Scheme 2A). The intramolecular trimethylenemethane diyl [3+2] cycloaddition of $\mathbf{4 0}$ led to the formation of angular fused triquinane $\mathbf{4 1}$ in $98 \%$ yield. The authors suggested that an intramolecular cycloaddition of the diazo group and allene $\mathbf{3 8}$ produces tetrahydrocyclopentapyrazole 39. Extrusion of nitrogen from the newly formed 39 produces diyl 40, which undergoes $[3+2]$ cycloaddition to produce the angular fused triquinane $\mathbf{4 1}$.

With the successful preparation of angular fused triquinane $\mathbf{4 1}$ by trimethylenemethane diyl [3 +2$]$ cycloaddition [29], enabled the synthesis of (-)-crinipellin A (15) [30] and waihoensene (16) [31] by Lee and co-workers in 2014 and 2017, respectively (Scheme 2B and Scheme 2C). The synthesis of (-)-crinipellin A (15) began with the treatment of hydrazone $\mathbf{4 2}$ with sodium hydride under reflux to produce the tetraquinane 46 in $87 \%$ yield [30] (Scheme 2B). The authors suggested that the diazo compound $\mathbf{4 3}$ formed undergoes an intramolecular cycloaddition to give $\mathbf{4 4}$. Freshly prepared $\mathbf{4 4}$ was converted to diyl $\mathbf{4 5}$ followed by another cycloaddition to give the tetraquinane $\mathbf{4 6}$. A four-step synthesis from the tetraquinane $\mathbf{4 6}$ gave diketone 47. Treatment of sulfoximine 48 with $n$-butyllithium generated the corresponding anion, which selectively attacked the C-8 ketone moiety of $\mathbf{4 7}$ to give alcohol 49 in $\beta$-configuration in $80 \%$ yield [32]. Chemoselective and stereoselective reduction of the $\mathrm{C}-\mathbf{9}$ ketone of $\mathbf{4 9}$ was accomplished by treatment with $\mathrm{NaBH}(\mathrm{OAc})_{3}[33$ ] and produced 50 after a two-step synthesis. Removal of the sulfoximine group in $\mathbf{5 0}$ upon refluxing in toluene and subsequent epoxidation afforded $\mathbf{5 1}$ [32], which was converted to (-)-crinipelline A (15) in two steps.

The synthesis of waihoensene (16) commenced with the conversion of aldehyde 52a to the corresponding hydrazone $\mathbf{5 2 b}$, which was treated with sodium hydride under reflux to give $\mathbf{5 6}$ in $83 \%$ yield over two steps [31] (Scheme 2C). This transformation was rationalized as follows: freshly prepared 52b was converted to diazo $\mathbf{5 3}$, which was subjected to $[3+2]$ cycloaddition to give adduct 54. Formation of diyl $\mathbf{5 5}$ from $\mathbf{5 4}$ and subsequent $[3+2]$ cycloaddition produced the tetracyclic compound 56. Dihydroxylation of freshly prepared 56 with $\mathrm{OsO}_{4}$ and then selective tosylation afforded $\mathbf{5 7}$ in $39 \%$ yield over two steps. Exposure of $\mathbf{5 7}$ to DBU upon heating gave the elimination product 58, which was subjected to an oxidative rearrangement with PDC to give enone $\mathbf{5 9}$ in $68 \%$ yield. Copper-mediated conjugated addition of methyllithium to enone $\mathbf{5 9}$ in the presence of boron trifluoride ether [34,35] produced desired ketone $\mathbf{6 0}$ in $75 \%$ yield. The resultant ketone $\mathbf{6 0}$ was converted to waihoensene (16) in two steps.

\section{Palladium-catalyzed carboxylative trimethylenemethane cycloaddition}

In 1986, Trost and co-workers disclosed the palladium-catalyzed intermolecular carboxylative TMM [3 + 2] cycloaddition [36] (Scheme 3). Exposure of coumarin 61 to the silyl-substituted TMM precursor 62 in the presence of a catalytic amount of $\mathrm{Pd}\left(\mathrm{PPh}_{3}\right)_{4}$ afforded adduct $\mathbf{6 3}$ in $81 \%$ yield as a single diastereomer (Scheme 3A). Trost and co-workers proposed that the catalytic mechanism involves an oxidative addition of palla$\operatorname{dium}(0)$ into $\mathbf{6 2}$ affording the $\eta^{3}-\mathrm{Pd}$ TMM complex A [37] (Scheme 3B). Methyl trimethylsilyl carbonate (64) is formed as side product, which is in equilibrium with carbon dioxide and 


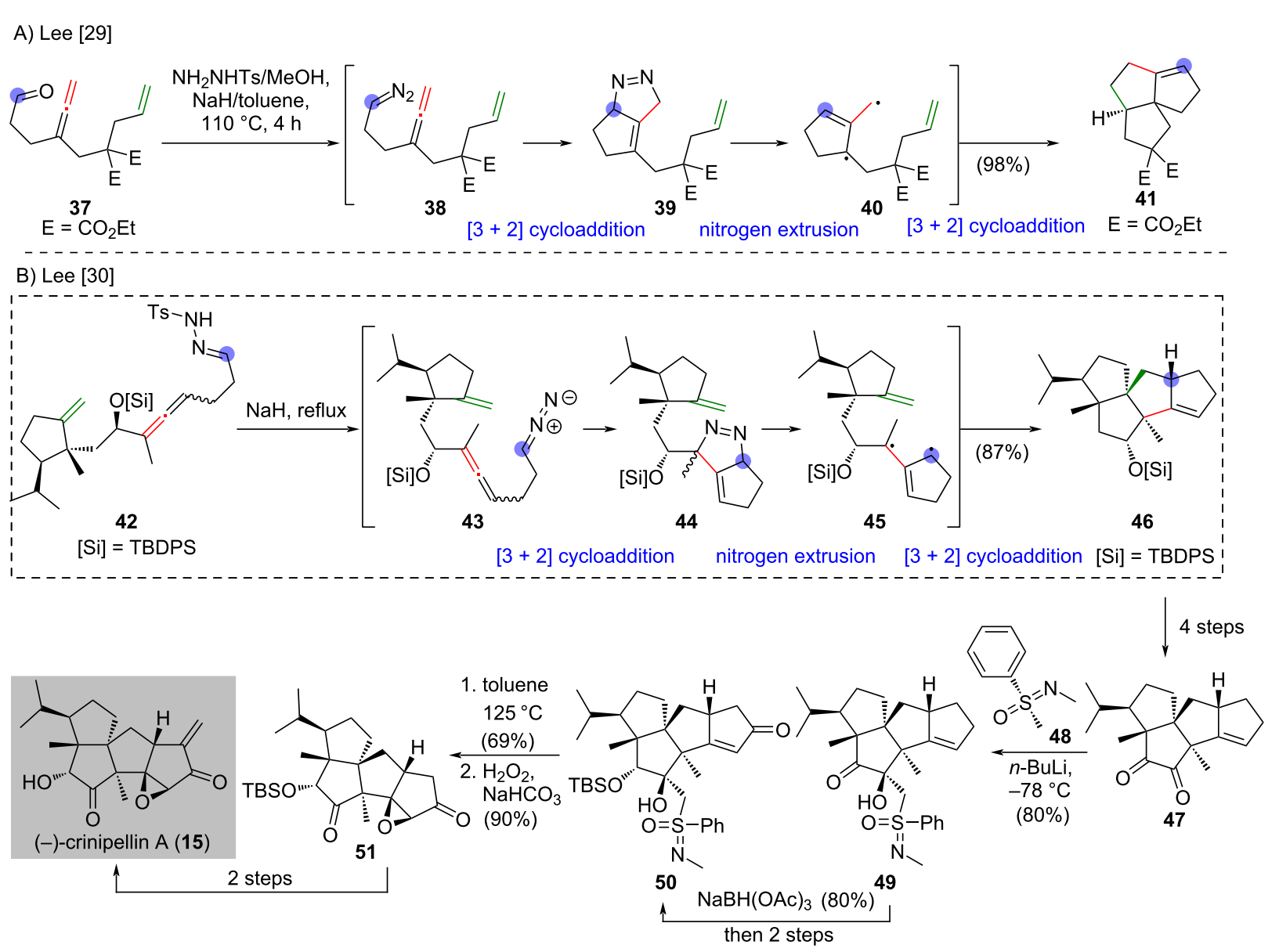

C) Lee [31]
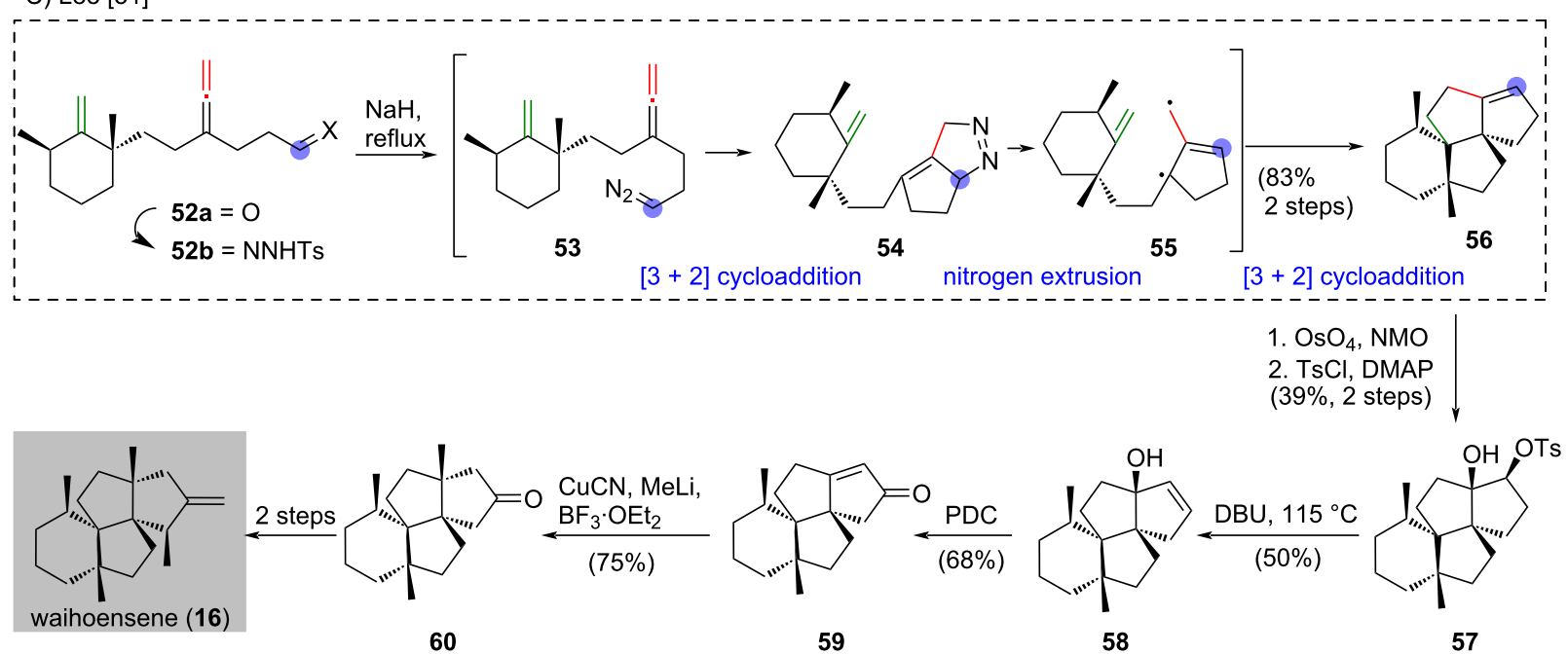

Scheme 2: (A) An intramolecular trimethylenemethane diyl [3 +2] cycloaddition with allenyl diazo compound $\mathbf{3 8}$ as a key intermediate to give angularfused triquinane 41 [29]. (B) Synthesis of (-)-crinipellin A (15) [30]. (C) Synthesis of waihoensene (16) [31].

methyl trimethylsilyl ether. The electron-rich end of complex A attacks the carbon dioxide to give carboxylate $\mathbf{B}$. Migration of the TMS group on carboxylate $\mathbf{B}$ generates the 1,3-dipole on $\mathbf{C}$ in the form of TMS carboxylate. An intermolecular [3 + 2] cycloaddition of $\mathbf{C}$ and alkene $\mathbf{D}$ (see Scheme 3B, inset) gives the cycloaddition adduct $\mathbf{E}$, which is converted to the corresponding carboxylic acid (not shown) upon reaction work-up. This elegant reaction was applied in the synthesis of marcfor- 
tine B (8), reported by Trost and co-workers in 2007 [38] and 2013 [39].

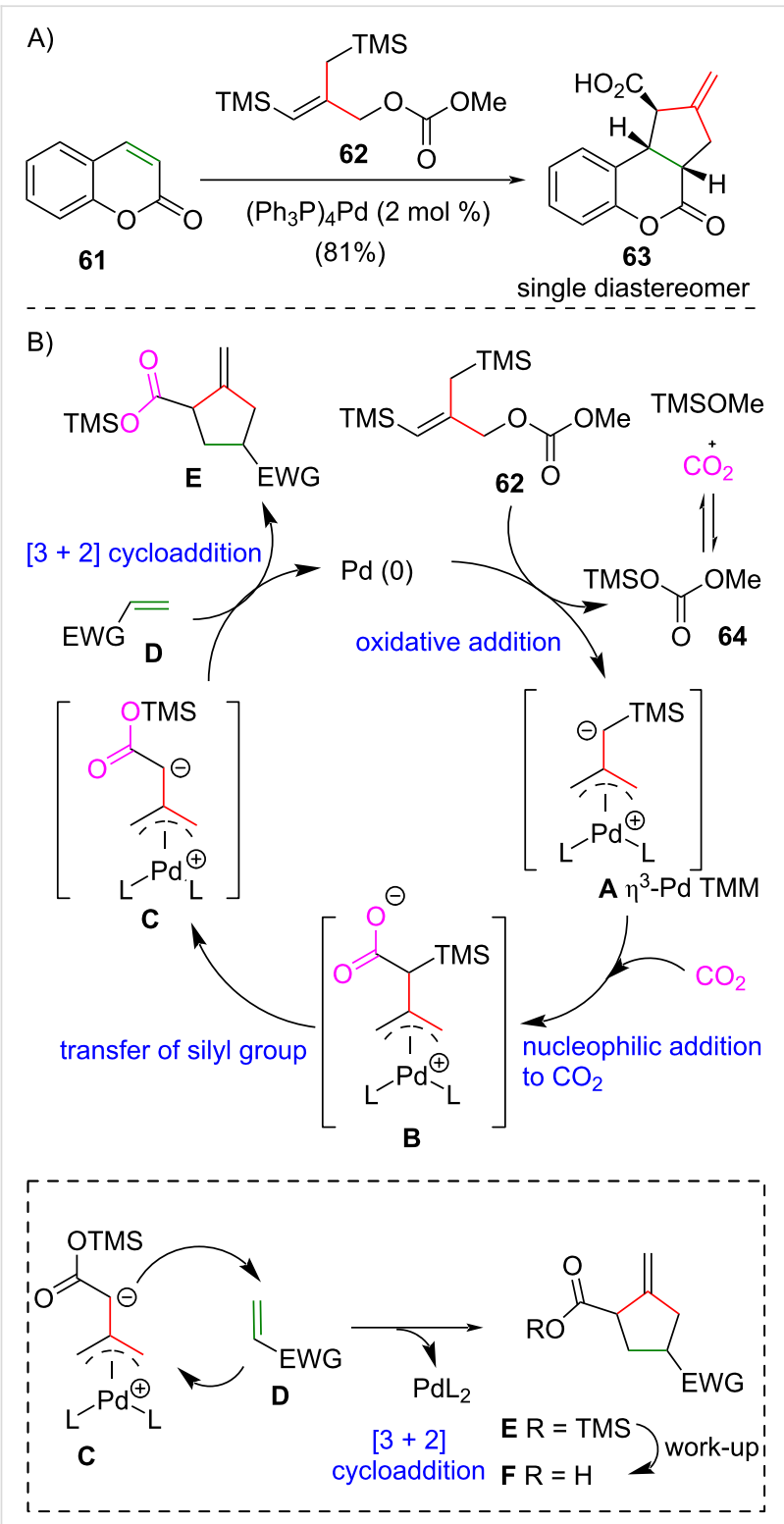

Scheme 3: (A) Palladium-catalyzed intermolecular carboxylative TMM cycloaddition [36]. (B) The proposed mechanism.

The synthesis of marcfortine B (8) began with palladium-catalyzed intermolecular carboxylatve TMM [3 + 2] cycloaddition [36] of enone $\mathbf{6 5}$ and TMM donor 62 to forge the highly-substituted spirocyclic cyclopentane 66a [38] (Scheme 4A). Methylation of the resultant cyclopentane 66a gave methyl ester $66 \mathbf{b}$ in $93 \%$ yield over two steps. A six-step synthesis from ester $\mathbf{6 6 b}$ gave $\alpha, \beta$-unsaturated amide 67 , which was treated with KHMDS to facilitate an intramolecular Michael addition to give lactam 68 in quantitative yield. The conversion of freshly prepared lactam 68 to xanthante ester 69 was achieved in three steps. Exposure of xanthante ester 69 to AIBN and a catalytic amount of tributylstannane [40] led to a radical cyclization, in which the resultant alkyl radical formed was trapped by AIBN to give a proposed nitrogen-centered radical 70. An 1,4-hydrogen abstraction of the nitrogen-centered radical on $\mathbf{7 0}$ produced carbon-centered radical 71, which underwent fragmentation to afford alkene $\mathbf{7 2}$ in $61 \%$ yield. Marcfortine B (8) was synthesized from alkene $\mathbf{7 2}$ in seven steps.

The enantioselective synthesis of marcfortine C (9) commenced with a catalytic asymmetric cyano-substituted TMM cycloaddition of oxindole 73 and TMM donor 75 with $\mathrm{Pd}(\mathrm{dba})_{2} / 74$ as catalyst to give a cycloaddition adduct (not shown) [39] (Scheme 4B). Subsequent treatement with $t$-BuOLi resulted in the isomerization of the exo-olefin followed by exposure to $n$-butyllithium and Davis' oxaziridine $\mathbf{7 6}$ to give 77 in $60 \%$ yield with $89 \%$ ee. A three-step synthesis from 77 gave $\alpha, \beta$ unsaturated amide 78, which underwent successive intramolecular Michael addition and hydrolytic nitrile reduction to give 79 in $46 \%$ yield in two steps. Extensive studies of the nitrile reduction eventually identified that $\mathrm{Et}_{3} \mathrm{Al}$ and DIBAL-H could effectively reduce the nitrile group to the corresponding aldehyde and treatment with $\mathrm{NaBH}_{4}$ afforded alcohol 79. Alcohol 79 was converted into the corresponding xanthate ester 80. This ester 80 was exposed to an excessive amount of AIBN and $\mathrm{N}, \mathrm{O}$ bis(trimethylsilyl)acetamide in the presence of a catalytic amount of tributylstannane producing bicyclo[2.2.2]diazaoctane 81 in 54\% yield. The authors mentioned that the employment of the previously reported conditions for the radical cyclization in the synthesis of marcfortine B (8) led to the decomposition of the starting material. It was suggested that the MOM group of $\mathbf{8 0}$ may contribute to undesired side reactions. Synthesis of marcfortine $\mathrm{C}(\mathbf{9})$ was accomplished from $\mathbf{8 1}$ in two steps.

\section{Phosphine-catalyzed [3 + 2] cycloaddition}

In 1995, Lu and co-workers reported a phosphine-catalyzed $[3+2]$ cycloaddition, employing electron-deficient olefins and either 2,3-butadienoates or 2-butynoates to give a cyclopentene as product [17] (Scheme 5A). The reaction between ethyl 2,3butadienoate (82) and diethyl fumarate $(\mathbf{8 3})$ in the presence of $10 \mathrm{~mol} \%$ of triphenylphosphine afforded trans -84 in $67 \%$ yield. Under the same conditions, the use of diethyl maleate in place of diethyl fumarate (83) will give cis-84 in 46\% yield (not shown). Lu and co-workers proposed that the catalytic mechanism involves a reaction between phosphine catalyst $\mathbf{A}$ and allene 82 to give $\mathbf{B}$ and/or $\mathbf{C}$ (Scheme 5B). Catalytic [3 + 2] cycloaddition of $\mathbf{B}$ and/or $\mathbf{C}$ and alkene $\mathbf{D}$ gives the cyclic intermediates $\mathbf{E}$ and $\mathbf{F}$ in an equilibrium state through a 1,2-proton transfer. The loss of phosphine catalyst from $\mathbf{E}$ or $\mathbf{F}$ affords the cycloaddition product $\mathbf{G}$ and the catalyst is regenerated. It is noteworthy that ethyl 2-butynoate ( $\mathbf{8 5}$ ) can be used as substrate 


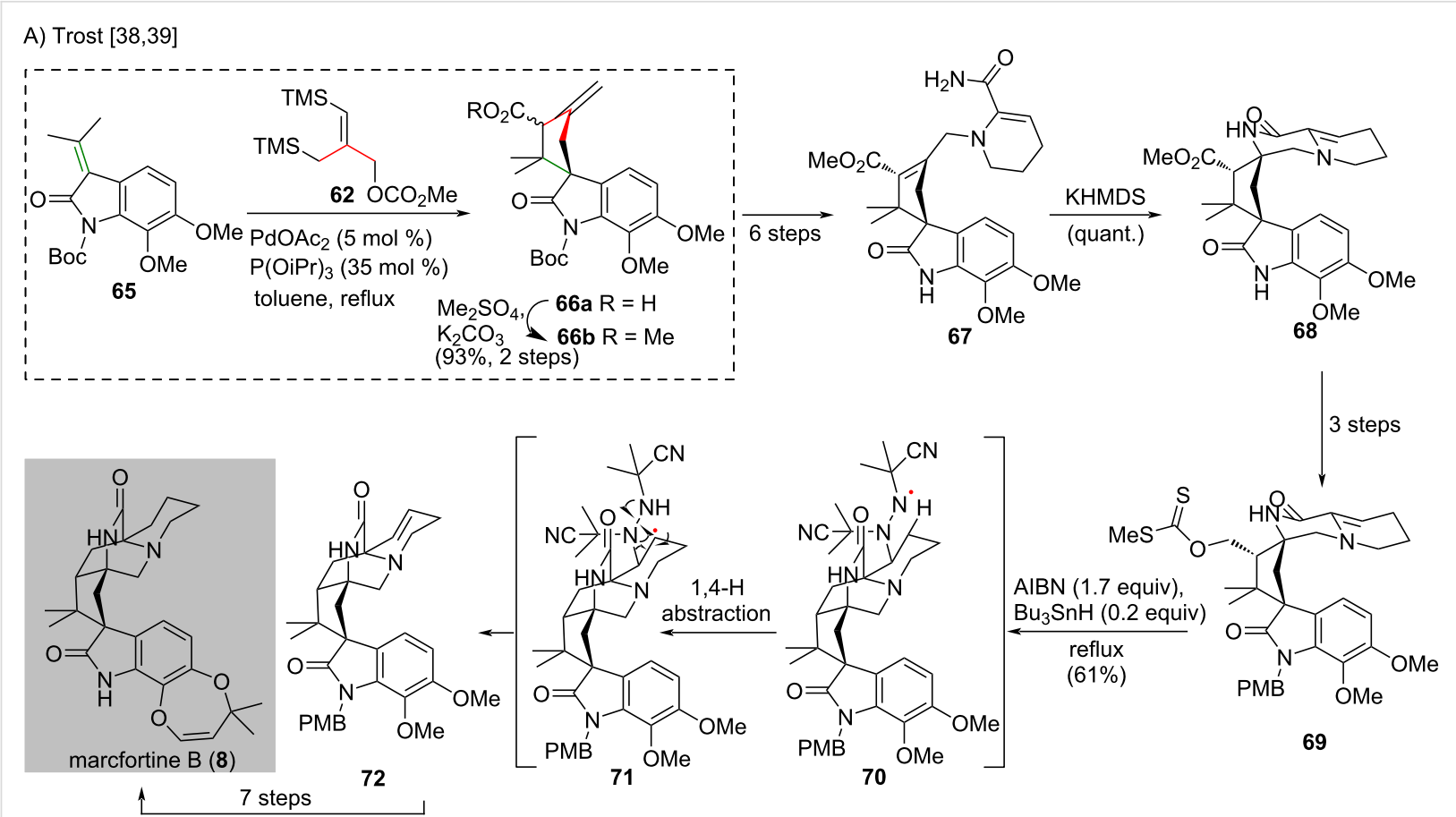

B) Trost [39]
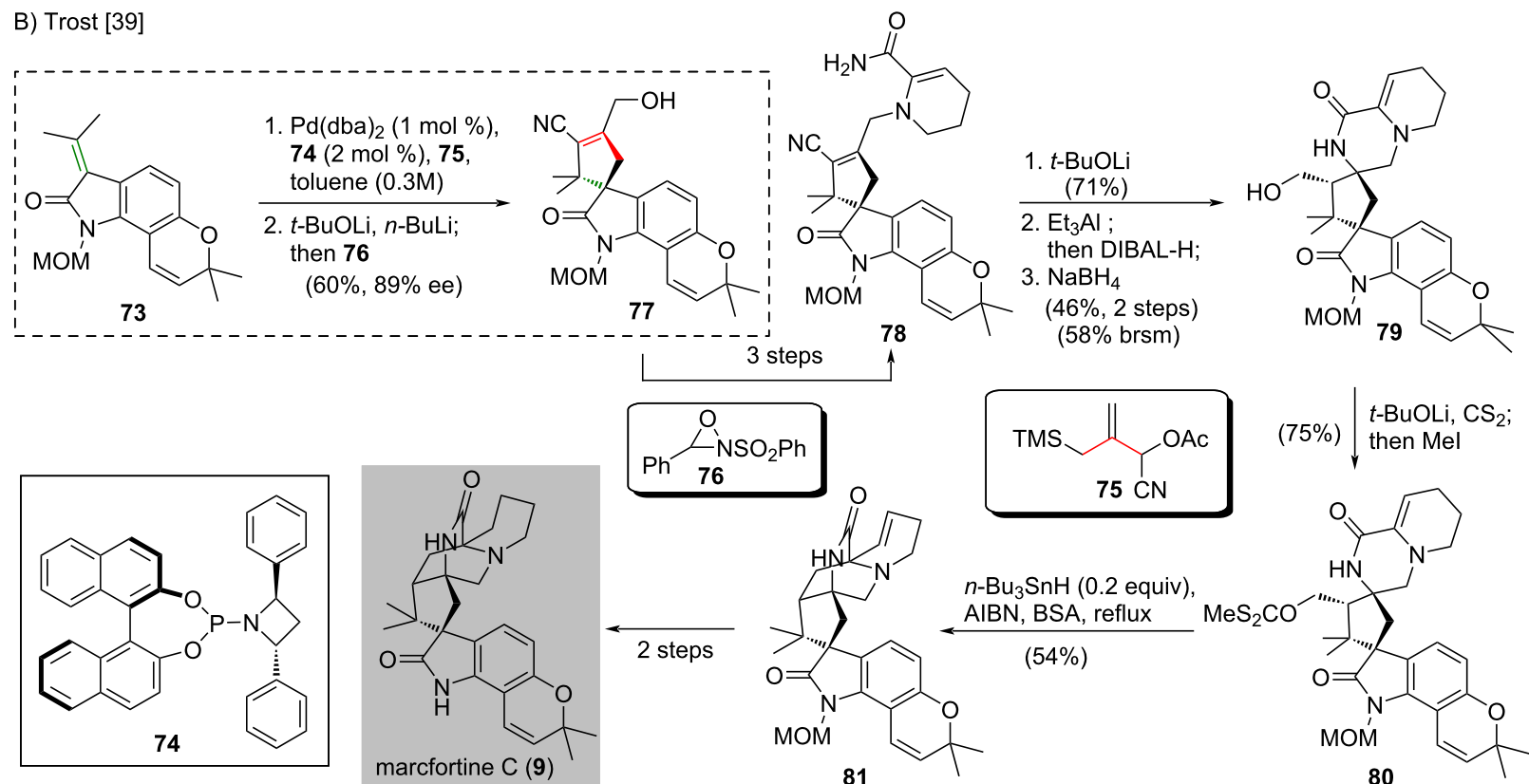

Scheme 4: Natural product syntheses that make use of palladium-catalyzed intermolecular [3 + 2] cycloadditions of TMM. (A) Synthesis of marcfortine $B(8)$ uses a palladium-catalyzed carboxylatve TMM [3+2] cycloaddition [38,39]. (B) Enantioselective synthesis of marcfortine $C(9)$ features a palladium-catalyzed asymmetric cyano-substituted TMM [3 + 2] cycloaddition [39].

in place of ethyl 2,3-butadienoate (82) in the phosphine-catalyzed [3 + 2] cycloaddition. Ethyl 2-butynoate (85) enters the catalytic cycle by reacting with phosphine catalyst $\mathbf{A}$ to give $\mathbf{H}$ and $\mathbf{C}$.

Some total syntheses of hexacyclic Daphniphyllum alkaloids were reported by Li's group (longeracinphyllin A (10) [41] and daphenylline (11) [42]) and Zhai's group (daphenylline (11) [43]), applying Lu's [3 + 2] cycloaddition (Scheme 6). The synthesis of longeracinphyllin A (10), which was reported by $\mathrm{Li}$ and co-workers in 2017, used a 1,1'-bis(diphenylphosphino)ferrocene-promoted [3 +2$]$ cycloaddition [44] of enedione $\mathbf{8 6}$ and allenoate $\mathbf{8 7}$ to give adduct $\mathbf{8 8}$ in $45 \%$ yield. This adduct $\mathbf{8 8}$ was treated with an excess of $\mathrm{LiCH}_{2} \mathrm{PO}(\mathrm{OMe})_{2}$ 

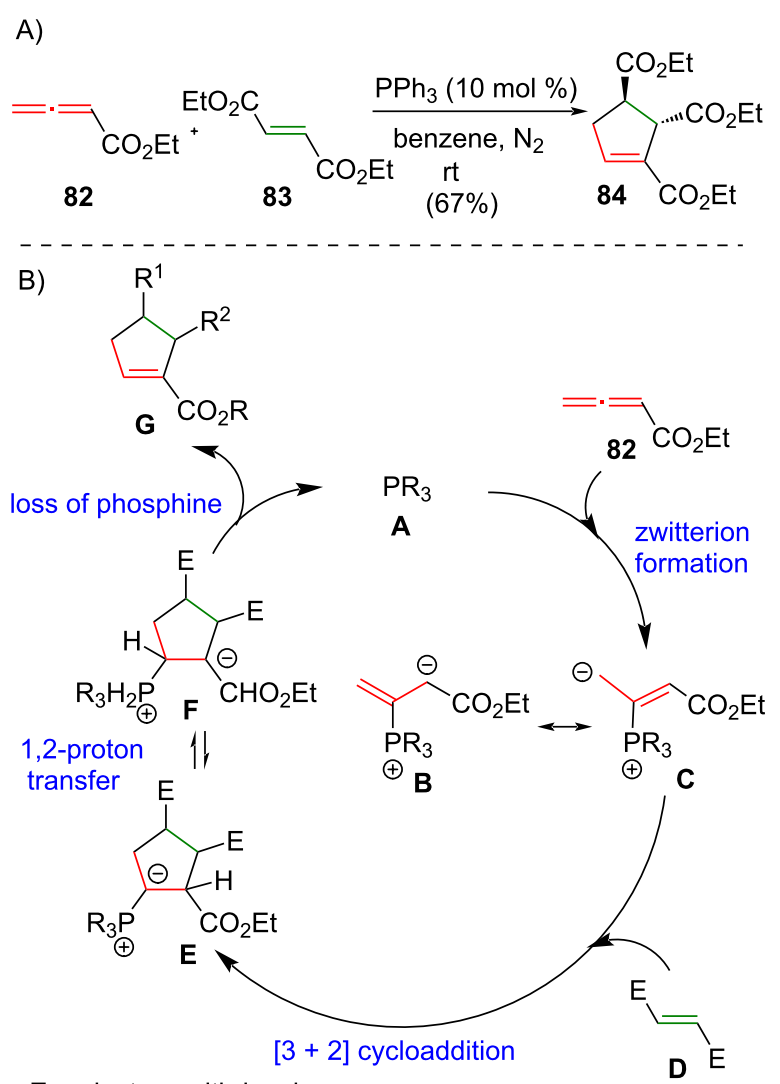

$\mathrm{E}=$ electron-withdrawing group

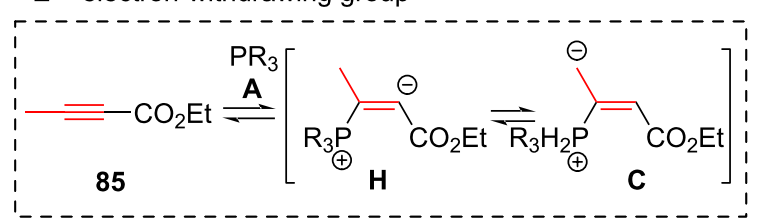

Scheme 5: (A) Phosphine-catalyzed [3 + 2] cycloaddition [17]. (B) The proposed mechanism.

to afford $\beta$-ketophosphonate $\mathbf{8 9}$ in $86 \%$ yield (Scheme 6A) [41]. Hydrogenation of $\mathbf{8 9}$ followed by an intramolecular Horner-Wadsworth-Emmons olefination produced hexacyclic enone 90 in $91 \%$ yield over two steps. The conversion of enone $\mathbf{9 0}$ to longeracinphyllin A (10) was achieved in three steps.

The syntheses of daphenylline (11) were reported by Li's group [42] and Zhai's group [43] independently in 2017 (Scheme 6B and Scheme 6C). In Li's synthesis, the common intermediate dienone 86 was subjected to a 1,1'-bis(diphenylphosphino)ferrocene-promoted [3 +2$]$ cycloaddition [41] with allenyl ketone 91 to give adduct 92a in 52\% yield (Scheme 6B). This adduct 92a underwent decarboxylation to afford 92b in $72 \%$ yield [42]. Exposure of freshly prepared 92b to triazabicyclodecene [45] led to a ring-expansion/aromatization/aldol cascade producing 93, which was reduced with $\mathrm{Et}_{3} \mathrm{SiH} / \mathrm{TFA}$ smoothly to give indane 94 in $68 \%$ yield over two steps. The freshly prepared indane 94 was converted to daphenylline (11) in two steps. The preparation of daphnipaxianine A and himalenine D (not shown) were also disclosed in the same work but are not described here.

Zhai's synthesis of daphenylline (11) used Lu's phosphine-catalyzed [3 + 2] cycloaddition [17] of enone 95 and tert-butyl 2-butynoate (96) with $\mathrm{PBu}_{3}$ and $\mathrm{K}_{2} \mathrm{CO}_{3} / \mathrm{MeOH}$ as additive to give the cycloaddition adduct 97 in $83 \%$ yield [43] (Scheme 6C). A seven-step synthesis from 97 gave pentacyclic ketone 98. Pentacyclic ketone 98 was exposed to PTSA under reflux to give the Wagner-Meerwein rearrangement product 99 in $85 \%$ yield. The synthesis of daphenylline (11) was completed by a seven-step synthesis from benzofuran $\mathbf{9 9}$.

\section{Phosphine-catalyzed enantioselective [3 + 2] annulation}

In 2019, Lu and co-workers disclosed a novel chiral-phosphinecatalyzed enantioselective $[3+2]$ annulation of allenes and isoindigos to give an enantioenriched annulation adduct bearing vicinal quaternary stereocenters [46] (Scheme 7A). Both symmetric and unsymmetric isoindigos can undergo enantioselective $[3+2]$ annulation with an allene and produced a chiral adduct with high yield and high ee value. When unsymmetric isoindigo 100 was used as substrate, enantioselective [3+2] annulation with allene $\mathbf{1 0 1}$ in the presence of amino acidderived bifunctional phosphine 102 produced adduct 103 in $90 \%$ yield with $92 \%$ ee and $4: 1$ regioisomeric ratio (rr). The authors suggested that the observed regioselectivity could be rationalized by the proposed catalytic mechanism (Scheme 7B). The phosphine (i.e., $\mathrm{PR}_{3}, \mathbf{A}$ ) attacks the allene $\mathbf{1 0 1}$ to generate zwitterion intermediate $\mathbf{B}$, which is subjected to a less hindered attack by the isoindigo 100. The oxindole bearing a chlorine atom on isoindigo 100 makes C-3 more electron deficient than C-3', which results in the regioselective formation of intermediate $\mathbf{C}$. Cyclization of intermediate $\mathbf{C}$ gives $\mathbf{D}$ and subsequent proton transfer produces isomer $\mathbf{E}$. It undergoes elimination to afford the annulation product $\mathbf{1 0 3}$ and the phosphine catalyst $\mathbf{A}$ is regenerated.

In the same work, $\mathrm{Lu}$ and co-workers applied the enantioselective $[3+2]$ annulation to complete the formal synthesis of (-)-ditryptophenaline (12) [46] (Scheme 7C). The synthesis began with the catalytic asymmetric $[3+2]$ annulation of symmetric isoindigo 104 and allene 101 with chiral phosphine catalyst $\mathbf{1 0 2}$ to give spirocyclic adduct $\mathbf{1 0 5}$ in $93 \%$ yield with $99 \%$ ee. The freshly prepared enantioenriched adduct 105 was subjected to ozonolysis [47] followed by decarboxylation to give bisoxindole 106 in 68\% yield over two steps. Conversion of $\mathbf{1 0 6}$ to the corresponding acetal and subsequent allylation afforded $\mathbf{1 0 8}$ in $86 \%$ yield over two steps. A two-step synthesis from $\mathbf{1 0 8}$ 


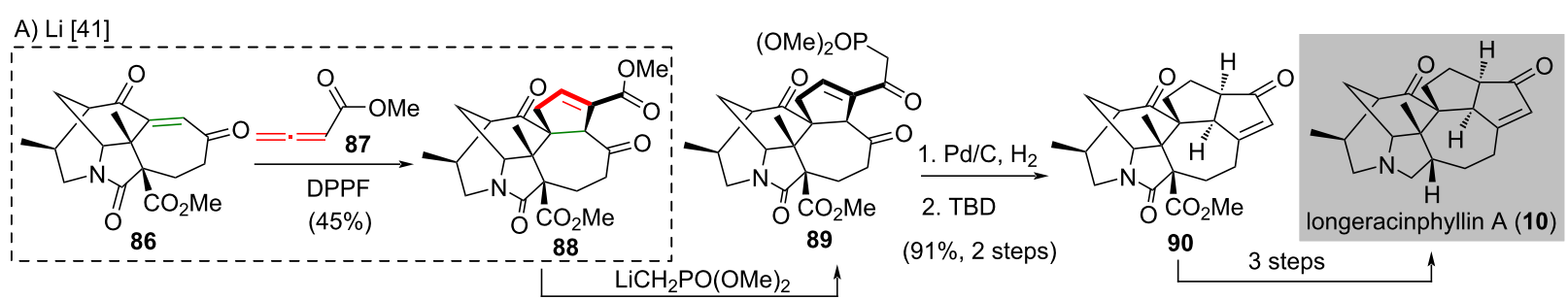

B) Li [42]
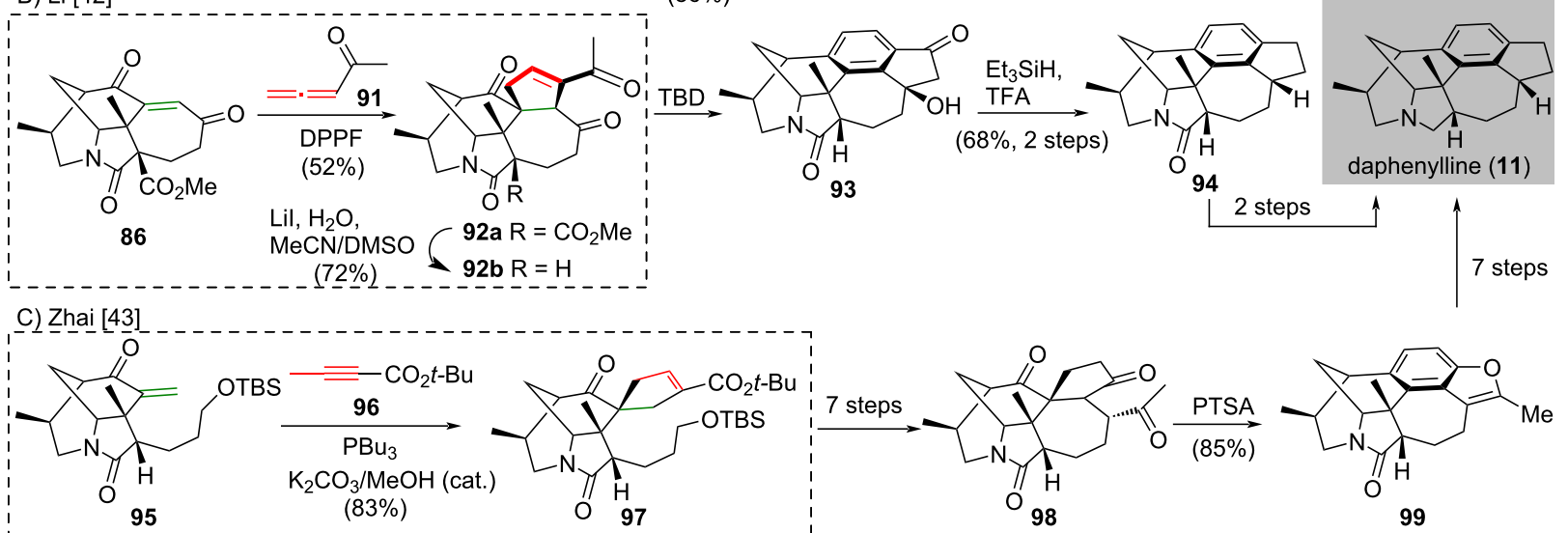

Scheme 6: Lu's [3 + 2] cycloaddition in natural product synthesis. (A) Synthesis of longeracinphyllin A (10) [41]. (B) Synthesis of daphenylline (11) [42]. (C) Synthesis of daphenylline (11) [43].

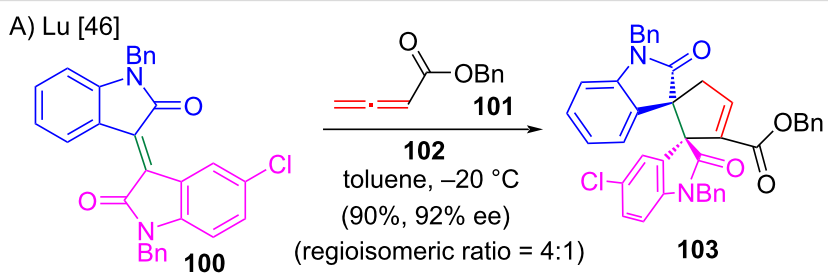

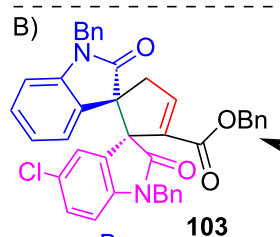

Bn
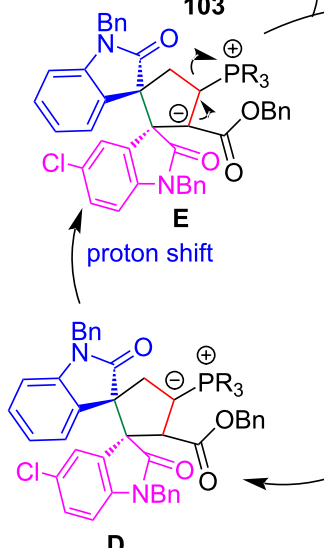

(regioisomeric ratio $=4: 1$ )

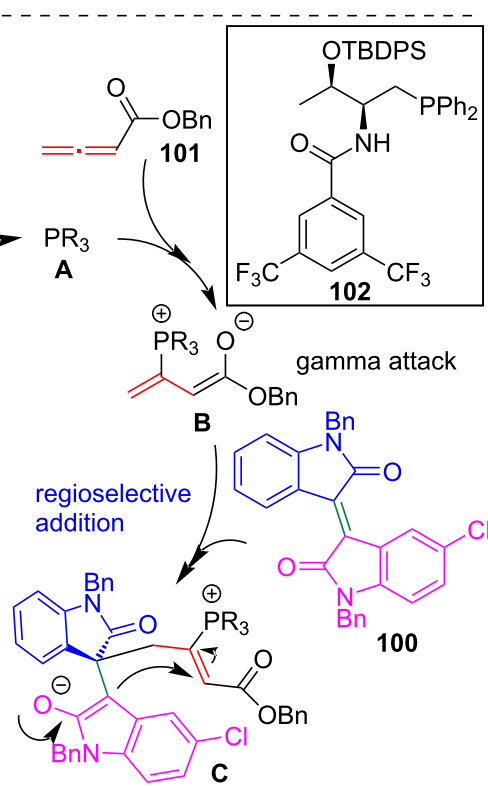

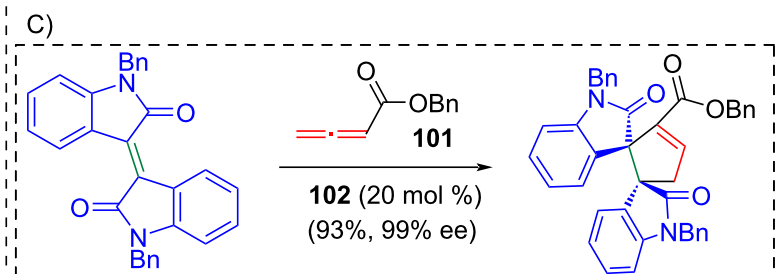

105

\begin{tabular}{l|l} 
1. $\mathrm{O}_{3}$; then $\mathrm{Zn}$ & 2. $\mathrm{Et}_{3} \mathrm{~N}$, reflux
\end{tabular} $\mathrm{AcOH}$, reflux $(68 \%, 2$ steps $)$
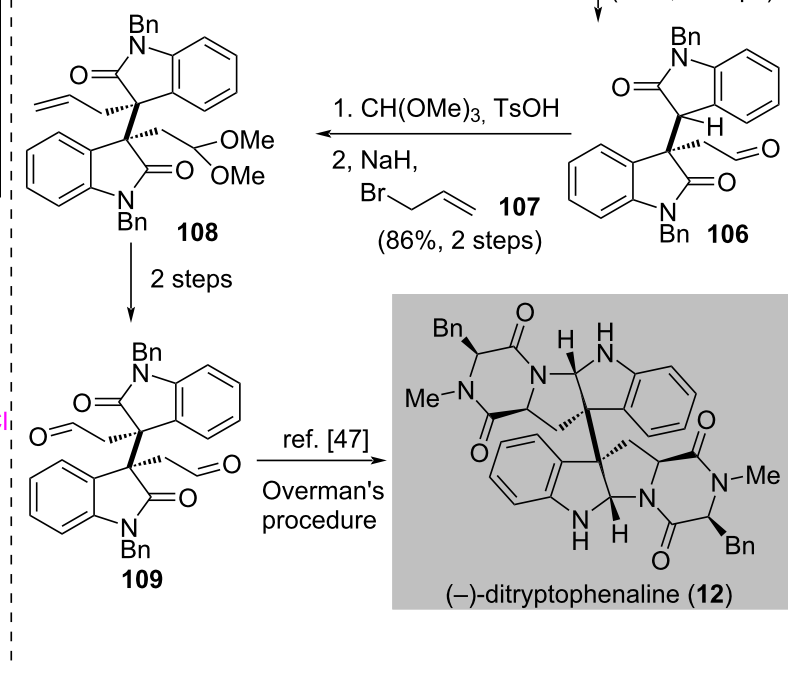

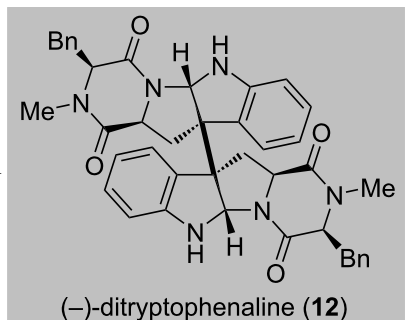

Scheme 7: (A) Phosphine-catalyzed [3 + 2] annulation of unsymmetric isoindigo 100 with allene in the preparation of spiro adduct 103 [46]. (B) The proposed catalytic cycle. (C) Application of phosphine-catalyzed asymmetric [3+2] annulation to prepare the chiral adduct 105 with symmetric isoindigo 104 in the formal synthesis of (-)-ditryptophenaline (12). 
produced 109, which was converted to (-)-ditryptophenaline (12) by using Overman's protocol [48].

\section{Rhodium-catalyzed [3 + 2] cycloaddition}

In 2014, Yang and co-workers reported an efficient rhodiumcatalyzed intramolecular [3+2] cycloaddition of $\mathbf{1 1 0}$ to give [3.3.0] and [3.4.0] bicyclic systems bearing two quaternary atoms at the bridgehead position [49]. For instance, enynol 110 was treated with $5 \mathrm{~mol} \%$ of $\left[\mathrm{RhCl}(\mathrm{CO})_{2}\right]_{2}$ and carbon monoxide to afford a [3.3.0] bicycle $\mathbf{1 1 1}$ in $87 \%$ yield (Scheme 8A). The proposed catalytic cycle of this elegant rhodium-catalyzed intramolecular $[3+2]$ cycloaddition begins with the reaction between the rhodium catalyst $\mathrm{Rh}(\mathrm{I}) \mathrm{LCl}$ and alcohol $\mathbf{1 1 0}$ to give complex A through alcoholysis [50,51] (Scheme 8B). Rh(I)mediated retro-propargylation of the homopropargyl alcohol A afforded complex B. It undergoes an intramolecular Michael addition [52,53] with the allenyl rhodium to the enal and gives the allenyl rhodium species C. A Conia-ene-type reaction [54] between the Rhoda-enolate species and the allene of complex $\mathbf{C}$ produces the desired [3.3.0] bicycle D. Protonolysis [55-57] of complex D with the alcohol 110 gives bicyclic product 111 and regenerates the rhodium complex $\mathbf{A}$. This elegant method has been successfully applied by the same research group in their synthesis of lingzhiol (17) [49], lycojaponicumin C (18) [58] and sinensilactam A (20) [59] (Scheme 9).

The synthesis of (-)-lingzhiol (17) was reported by Yang and co-workers in 2014 [49] (Scheme 9A). The synthesis began with the conversion of ketone $\mathbf{1 1 2}$ into alcohol $\mathbf{1 1 3}$ in four steps, which involved a hypervalent iodine-mediated ring expansion [60]. A two-step synthesis from 113 gave epoxide 114. Epoxide 114 was converted to the corresponding $\beta$-ketoester and subsequent treatment with Waser's reagent 116 [61] afforded alkyne $\mathbf{1 1 7}$ in $62 \%$ yield over two steps. Enyne 118, which was prepared in two steps from 117, was subjected to rhodium-catalyzed intramolecular [3+2] cycloaddition in the presence of carbon monoxide to give tricycle 119 bearing the desired vicinal quaternary carbon stereocenters in $86 \%$ yield. Reduction of aldehyde 119 and subsequent transesterification produced a lactone (not shown). It was exposed to $\mathrm{SeO}_{2}$ to install the allylic hydroxy group to give $\mathbf{1 2 0}$ in $65 \%$ yield. Upon catalytic hydrogenation of $\mathbf{1 2 0}$, alcohol $\mathbf{1 2 1}$ was formed. This alcohol $\mathbf{1 2 0}$ was subjected to a bromination [62]/oxidation sequence followed by demethylation to produce (-)-lingzhiol (17).

After the elegant synthesis of (-)-lingzhiol (17) was reported by Yang's group [49], the same research group disclosed the synthesis of lycojaponicumin C (18) [58] and sinensilactam A (20) [59] in 2017 and 2018, respectively, featuring the rhodium-catalyzed intramolecular [3+2] cycloaddition as the key reaction
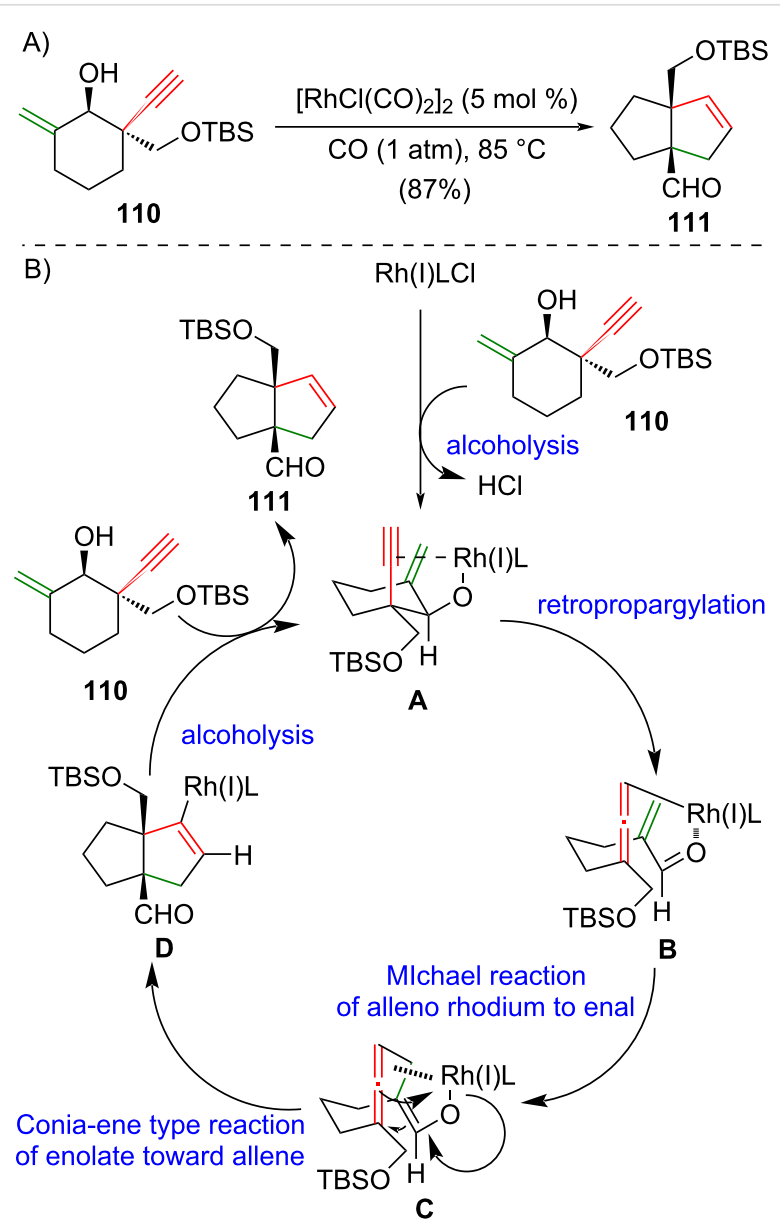

Scheme 8: (A) Rhodium-catalyzed intracmolecular [3 + 2] cycloaddition [49]. (B) The proposed catalytic cycle of the reaction.

(Scheme 9B and Scheme 9C). Enyne 123, which was prepared from enone $\mathbf{1 2 2}$ in four steps, was subjected to the rhodium-catalyzed intramolecular $[3+2]$ cycloaddition under carbon monooxide to give the desired bicyclic [3.3.0] aldehyde $\mathbf{1 2 4}$ in $88 \%$ yield. A seven-step synthesis from aldehyde $\mathbf{1 2 4}$ gave azide 125. It was converted to alcohol 126 in seven steps. Alcohol 126 was treated with LDA and vinylMgBr to facilitate a $\gamma$-OH directed 1,4-addition [63] to give C-7-vinylated tricycle 127 in 60\% yield (74\% yield, brsm). A two-step synthesis from 127 produced diene $\mathbf{1 2 8}$, which was subjected to ring-closing metathesis and subsequent Dess-Martin oxidation to give 129 in $63 \%$ yield over two steps. Tetracycle 130, which was prepared from 129 in one step, was converted to lycojaponicumin C (18) via Tu's protocol [64].

The synthesis of sinensilactam A (20) commenced with a threestep synthesis from ketoeseter 131 to give enone 132 [59] (Scheme 9C). Selective reduction of the ketone moiety of $\mathbf{1 3 2}$ was accomplished under Luche's conditions [65] in the presence of calcium chloride [63] to produce the desired alcohol 


\section{A) Yang [49]}

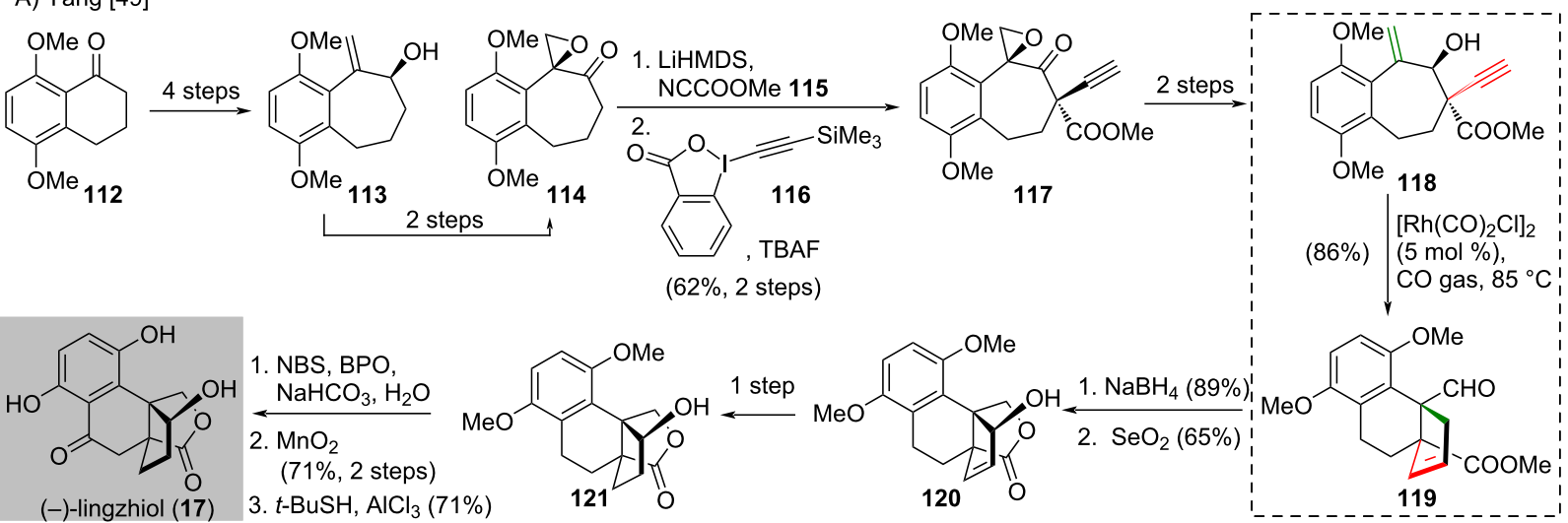

B) Yang [58]
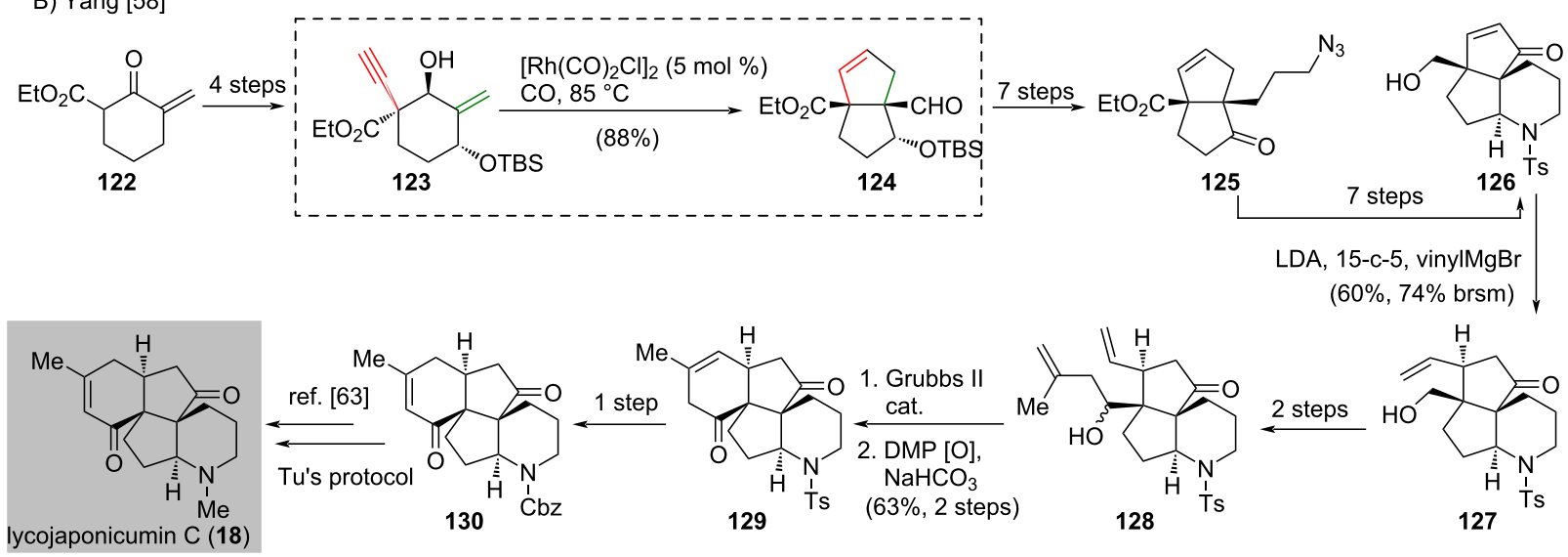

C) Yang [59]

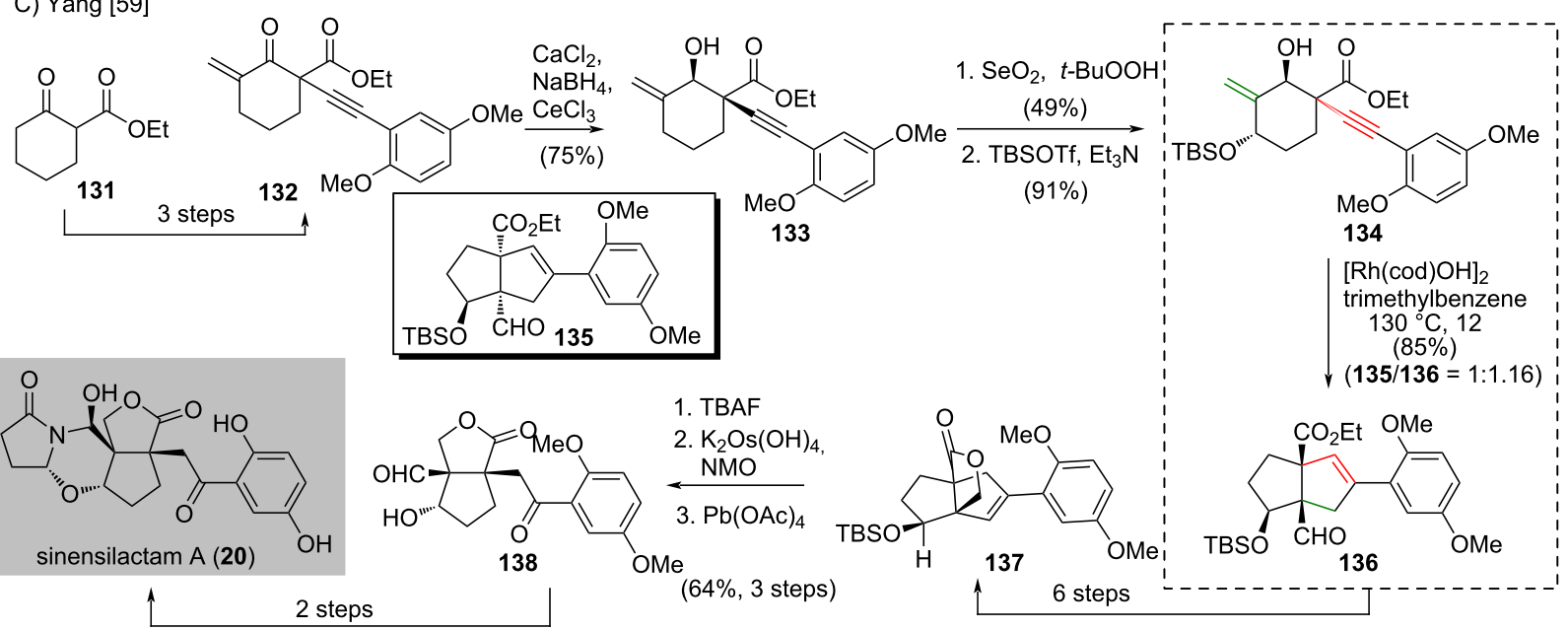

Scheme 9: Total synthesis of natural products reported by Yang and co-workers applying rhodium-catalyzed intramolecular [3+2] cycloaddition (A) Synthesis of (-)-lingzhiol (17) [49]. (B) Synthesis of lycojaponicumin C (18) [58]. (C) Synthesis of sinensilactam A (20) [59].

133 in $75 \%$ yield as a single diastereomer. Allylic oxidation of freshly prepared $\mathbf{1 3 3}$ with $\mathrm{SeO}_{2}$ followed by silylation with TBSOTf/Et ${ }_{3} \mathrm{~N}$ afforded enyne 134. Enyne 134 was subjected to rhodium-catalyzed intramolecular [3 +2$]$ cycloaddition with a catalytic amount of $[\mathrm{Rh}(\mathrm{cod}) \mathrm{OH}]_{2}$ to produce $\mathbf{1 3 5}$ and $\mathbf{1 3 6}$ in
$85 \%$ yield in the ratio of 1:1.16. A six-step synthesis from the major product 136 gave lactone 137. This compond was subjected to successive desilylation, $\mathrm{OsO}_{4}$-mediated dihydroxylation and subsequent oxidative cleavage of the $\mathrm{C}=\mathrm{C}$ double bond with $\mathrm{Pb}(\mathrm{OAc})_{4}$ to give ketoaldehyde 138 in $64 \%$ yield 
over three steps. The conversion of $\mathbf{1 3 8}$ to sinensilactam A (20) was achieved in two steps.

\section{Platinum-catalyzed [3 +2$]$ cycloaddition}

The platinum-catalyzed intermolecular [3+2] cycloaddition of propargyl ether derivatives and vinyl ether producing polycyclic indoles was disclosed by Iwasawa and co-workers in 2011 [18,66] (Scheme 10A). Treatment of Boc-protected aniline $\mathbf{1 3 9}$ and $n$-butyl vinyl ether (140) with a platinum(II) catalyst afforded tricyclic indole $\mathbf{1 4 1}$ in $83 \%$ yield. The authors suggested that this catalytic $[3+2]$ cycloaddition reaction may involve an $\alpha, \beta$-unsaturated carbene complex intermediate and a mechanism was proposed (Scheme 10B). An nucleophilic attack of the amine nitrogen onto the alkyne $\mathbf{1 3 9}$ under the effect of activated $\mathrm{Pt}(\mathrm{II})$ A produces zwitterionic intermediate B. Elimination of the methoxy group from zwitterion $\mathbf{B}$ generates the $\alpha, \beta$-unsaturated carbene complex intermediate $\mathbf{C}$. $\mathbf{C}$ is subjected to the nucleophilic attack of $n$-butyl vinyl ether (140) and generates alkenyl metallic intermediate $\mathbf{D}$. Intramolecular nucleophilic attack onto the oxonium carbon of $\mathbf{D}$ affords the $[3+2]$ cycloaddition product $\mathbf{1 4 1}$ with regeneration of the catalyst A.

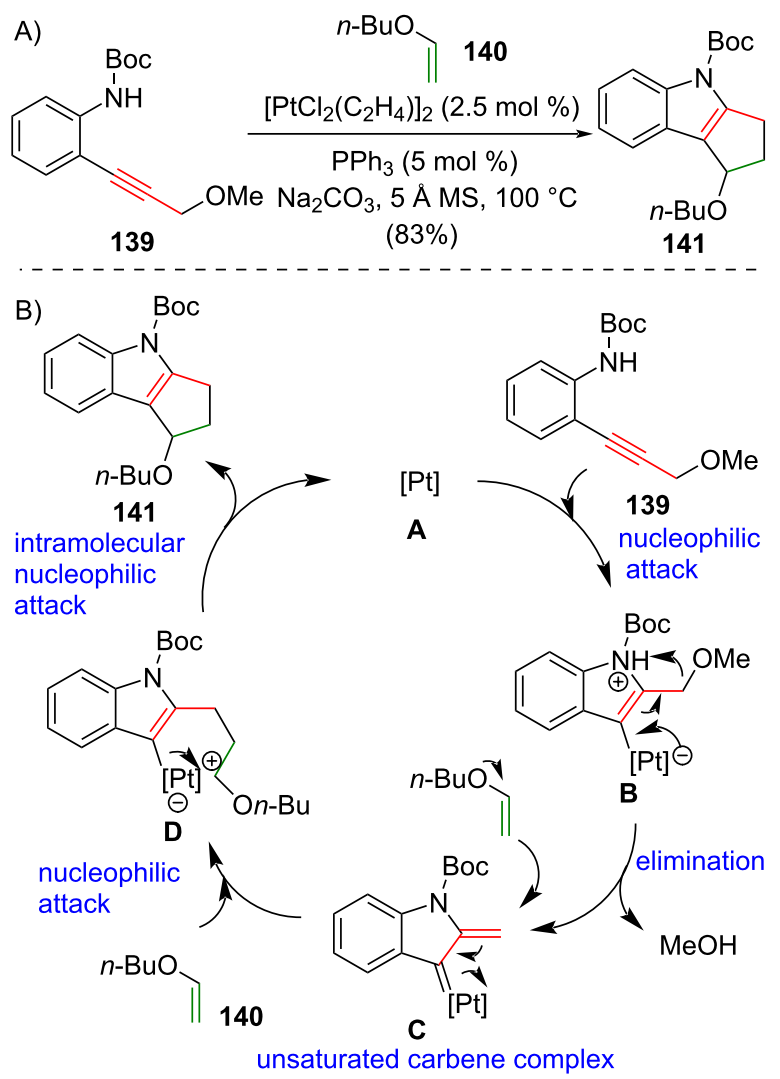

Scheme 10: (A) Platinum(II)-catalyzed intermolecular [3 + 2] cycloaddition of propargyl ether 139 and $n$-butyl vinyl ether (140) gives tricyclic indole 141 [18,66]. (B) The proposed mechanism.
In 2020, Ye and co-workers used a platinum-catalyzed intramolecular [3+2] cycloaddition of a propargylic ketal derivative to complete the total synthesis of Kopsia indole alkaloids [67] (Scheme 11). The platinum-catalyzed intramolecular [3+2]
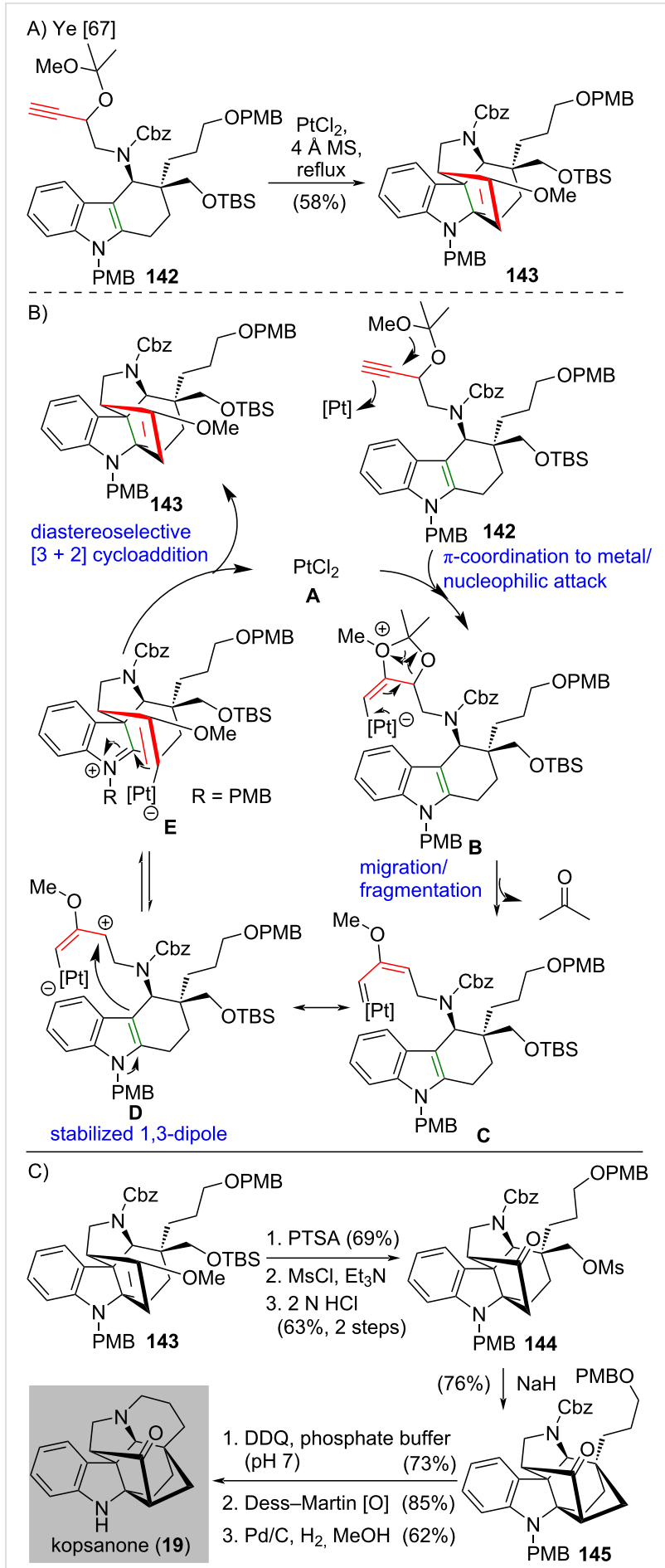

Scheme 11: (A) Platinum-catalyzed intramolecular [3 + 2] cycloaddition of propargylic ketal derivative 142 to give indoline 143 [67]. (B) The proposed catalytic mechanism. (C) The completion of total synthesis of kopsanone (19). 
cycloaddition of propargylic ketal derivative 142 afforded indoline $\mathbf{1 4 3}$ in 58\% yield, which possesses three contiguous stereocenters with vicinal all-carbon quaternary centers. (Scheme 11A). According to the proposed mechanism, coordination of the triple bond of $\mathbf{1 4 2}$ to the electrophilic platinum complex A followed by intramolecular nucleophilic attack by the methoxy group gives complex B (Scheme 11B). A facile migration-fragmentation process of complex $\mathbf{B}$ eliminates a ketone through fragmentation and produces metal-carbene intermediate $\mathbf{C}$. The freshly prepared metal-carbene $\mathbf{C}$ is equilibrated to stabilized 1,3-dipole D. D undergoes a diastereoselective [3+2] cycloaddition to give indoline 143 and the active platinum catalyst $\mathbf{A}$ is regenerated. After the successful preparation of indoline 143, the synthesis of kopsanone (19) is accomplished (Scheme 11C). Indoline $\mathbf{1 4 3}$ was converted to ketone $\mathbf{1 4 4}$ in three steps, which was subjected to a nucleophilic substitution to give the cyclization product $\mathbf{1 4 5}$ in $76 \%$ yield. The hexacyclic compound 145 was converted to kopsanone (19) in three steps.

\section{Miscellaneous}

In 2012, Wang and co-workers reported a Lewis acid-catalyzed intramolecular [3+2] cross-cycloaddition (IMCC) of cyclopropane 1,1-diesters with non-activated alkene to generate bridged [n.2.1] carbocyclic skeletons, which is applied to the synthesis of phyllocladanol (21) [68] (Scheme 12A). The IMCC precursor 147 was prepared from aldehyde 146 in nine steps. The IMCC precursor 147 underwent an intramolecular crosscycloaddition catalyzed by tin tetrachloride to give tetracycle 149 in $81 \%$ yield. The authors suggested that the intramolecular $[3+2]$ cross-cycloaddition of the less-substituted external carbon atom in the $\mathrm{C}=\mathrm{C}$ double bond results in the formation of the more stable internal carbenium (i.e., 148) and promotes IMCC to give the bridged [3.2.1] octane 149. The transformation of 149 to phyllocladanol (21) was accomplished in four steps.

In 2016, Winne and co-workers reported that (5,6-dihydro-1,4dithiin-2-yl)methanol (151) can be served as a allyl-cation equivalent for the $[3+2]$ cycloaddition and was applied in the synthesis of ( \pm )-cuparene (13) [69] (Scheme 12B). An intermolecular [3+2] cycloaddition of tetrasubstituted alkene $\mathbf{1 5 0}$ and the dhdt-2-methanol reagent $\mathbf{1 5 1}$ under the effect of trifluoroacetic acid produced adduct $\mathbf{1 5 4}$ in $52 \%$ yield. The authors identified that the cyclic nature of the dhdt-2-methanol reagent 151 is essential for the cycloaddition to take place. The use of noncyclic analogues did not give the cycloaddition product. It is suggested that the restricted rotational freedom of $\mathbf{1 5 1}$ and the related enforced conjugation of the sulfur lone pair may block certain undesired cation reactions. Cycloaddition product $\mathbf{1 5 4}$ was subjected to the hydrodesulfurization with Raney nickel as catalyst and subsequent catalytic hydrogenation produced $( \pm)$-cuparene $(\mathbf{1 3})$ in $90 \%$ yield.

\section{All-carbon [3 + 2] annulation in natural product synthesis}

The all-carbon $[3+2]$ cycloaddition demonstrated the ability to assemble intricate polycyclic structures in the synthesis of complex natural products. Besides the all-carbon $[3+2]$ cycloaddition reactions and the corresponding applications described above, the all-carbon [3 + 2] annulation, which undergoes other possible mechanistic pathways other than cycloaddition, proved

A) Wang [68]

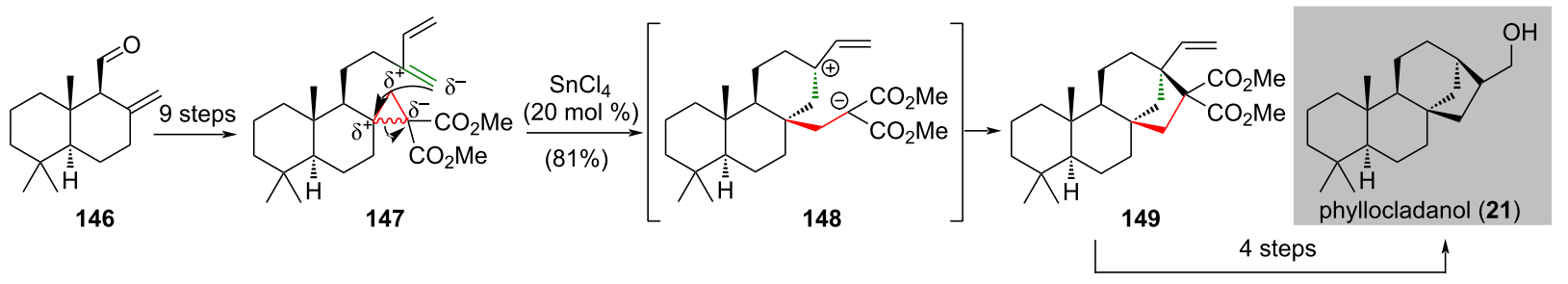

B) Winne [69]

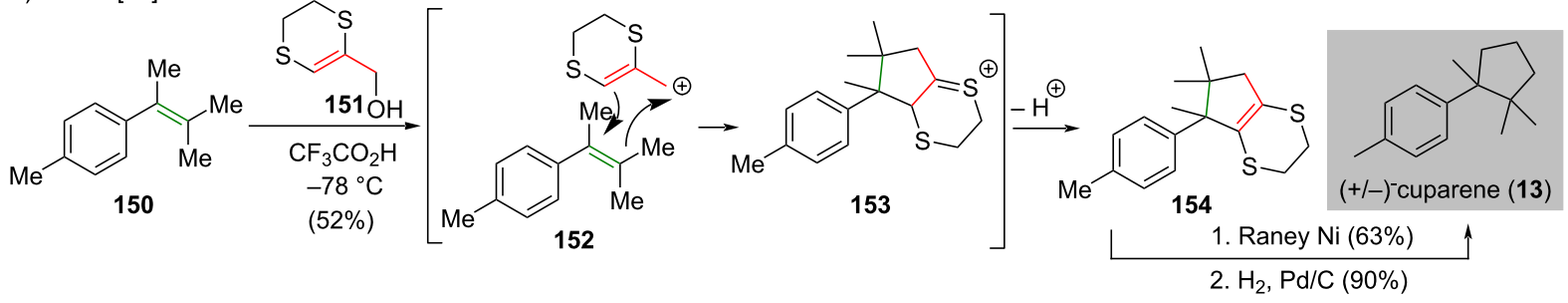

Scheme 12: (A) Synthesis of phyllocladanol (21) features a Lewis acid-catalyzed formal intramolecular [3 +2 ] cross-cycloaddition of cyclopropane 1,1-diesters with alkenes [68]. (B) (5,6-Dihydro-1,4-dithiin-2-yl)methanol 151 used as a versatile allyl-cation equivalent in [3 + 2] cycloaddition in the synthesis of $( \pm$ )-cuparene (13) [69]. 
its usefulness in forging highly-substituted five-membered carbocycles. These reactions have been applied successfully in the synthesis of complex natural products. In 2011, Curran and co-workers reported the synthesis of meloscine (158) featuring a tandem radical cyclization of a divinylcyclopropane [70] (Scheme 13A). Slow addition of tributylstannane and AIBN to a refluxing solution of cyclopropane $\mathbf{1 5 5}$ afforded 156 in 38\% yield. It was subjected to cleavage of the Boc group followed by $\mathrm{N}$-allylation to give $\mathbf{1 5 7}$ in $\mathbf{7 3 \%}$ yield over two steps. A ringclosing metathesis of freshly prepared $\mathbf{1 5 7}$ was effected by the second generation Hoveyda-Grubbs (HG II) catalyst and subsequent base-promoted epimerization produced meloscine (158) in $83 \%$ yield.

In 2017, Yang and co-workers disclosed the synthesis of (-)-pavidolide B (166) by using a thiyl-radical-mediated [3+2] annulation reaction to create four contiguous stereocenters on tricycle 162 in one step [71,72] (Scheme 13B). Exposure of ester 159 to $\mathrm{PhSH}$ [75], $p$-toluidine and a catalytic amount of $\operatorname{Ir}\left(\mathrm{dF}\left(\mathrm{CF}_{3}\right) \text { ppy }\right)_{2}$ (dtbbpy) $\mathrm{PF}_{6}$ under the irradiation of blue LED

A) Curran [70]

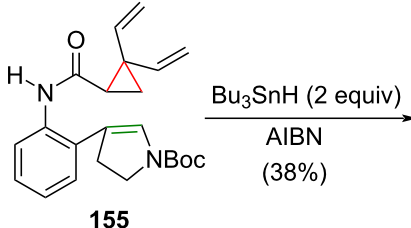

cascade radical annulation of divinylcyclopropan

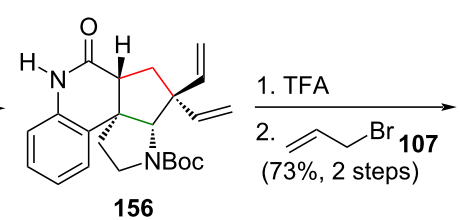

56<smiles>C=CCN1CC[C@]23c4ccccc4NC(=O)C2CC(C=C)(C=C)C13</smiles>

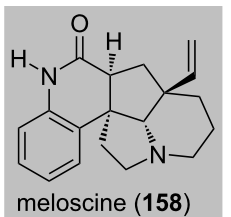

B) Yang $[71,72]$<smiles>CC=CC1[C@@H](C(OCC)OCC)C1(C(=O)OC)C(=O)O[C@H]1C=C(C)C(=O)C[C@H]1C(C)C</smiles>

$$
\mathrm{PhSH} \text {, }
$$

$\operatorname{Ir}\left(\mathrm{dF}\left(\mathrm{CF}_{3}\right) \text { ppy }\right)_{2}$ (dtbbpy)PF , $_{6}$ $p$-toluidine, blue LEDs

159

thiyl-radical-mediated $[3+2]$ annulation reaction<smiles>CCOC(C)C(C=CC(C)c1ccccc1)(CC(C)(C)C(=O)OC1C=C(C)C(=O)CC1C(C)C)C(=O)OC</smiles>

160

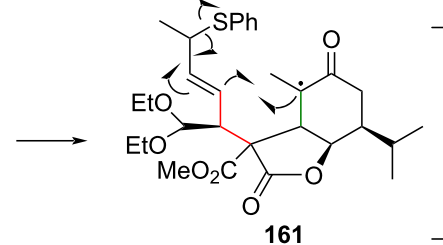

161 $(50 \%) \downarrow-P h S$

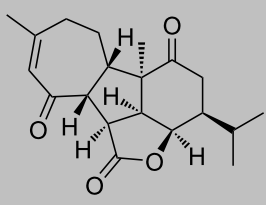

(-)-pavidolide B (166)

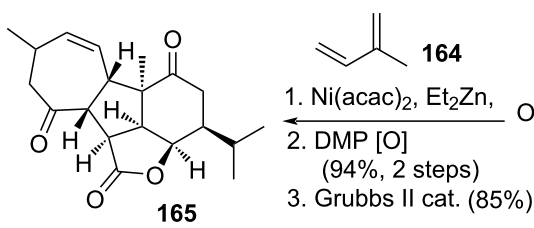

165

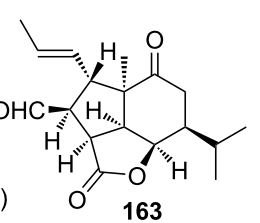

163
$\mathrm{Me}_{4} \mathrm{NOH} ; 120^{\circ} \mathrm{C}$ then $\mathrm{HCl}(2 \mathrm{M})$ $(90 \%)$

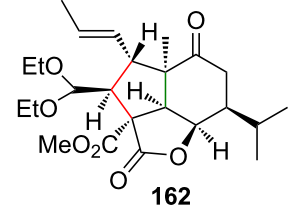

$\mathrm{RhCl}_{3}-\mathrm{H}_{2} \mathrm{O}, 100^{\circ} \mathrm{C}$, sealed tube $(95 \%)$

C) Zhai [73]

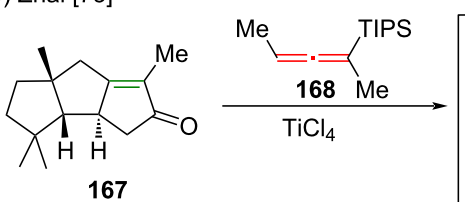

167

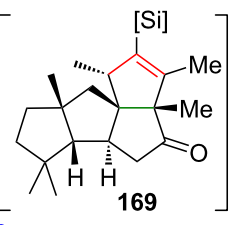

$[\mathrm{Si}]=\mathrm{TIPS}$

\section{then $\mathrm{BF}_{3}-(\mathrm{HOAc})_{2}$ $(89 \%)$ $(>4: 1$ dr@C5)}

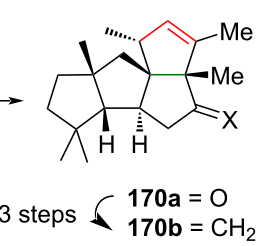

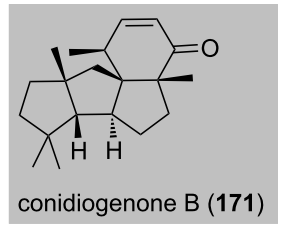

undesired conidiogenone $B$ (171)

Danheiser's $[3+2]$ annulation<smiles>CC1=C2C[C@]3(C)CCC(C)(C)[C@H]3[C@@H]2CC1=O</smiles>

167<smiles>CC=C=C(C)[In]S</smiles>

168

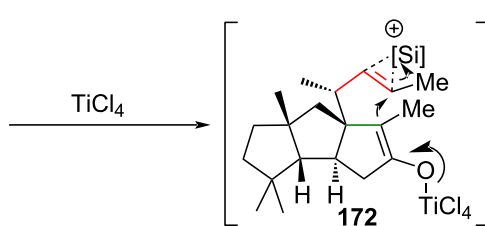

[Si] $=$ TIPS
[Si]

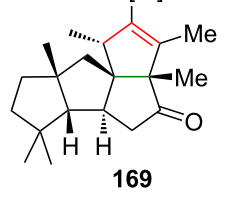

169

Scheme 13: The recent advances of $[3+2]$ annulation in natural product synthesis. (A) The preparation of meloscine (158) features a cascade radical annulation of divinylcyclopropane [70]. (B) Thiyl-radical-mediated [3+2] annulation reaction realizes the synthesis of $(-)$-pavidolide $B(166)$ [71,72]. (C) A Danheiser's [3 + 2] annulation en route to conidiogenone B (171) [73] (inset, the suggested mechanism based on Danheiser's proposal disclosed in 1981 [74].) 
light [76,77] afforded tricycle $\mathbf{1 6 2}$ in 50\% yield. The authors suggested that this process involves an intramolecular 5-exoconjugated addition of a radical on $\mathbf{1 6 0}$ to the enone and produces $\mathbf{1 6 1}$. The newly formed $\mathbf{1 6 1}$ was subjected to 5-exo radical addition to the allyl sulfane and subsequent loss of a thiyl radical produces 162. A successive hydrolysis/decarboxylation upon heating and cleavage of acetal on 162 afforded aldehyde 163 in $90 \%$ yield. Coupling of aldehyde 163 and isoprene (164) with $\mathrm{Ni}(\mathrm{acac})_{2}$ and diethylzinc [78] and then Dess-Martin oxidation gave a diene (not shown, 94\% yield over two steps), which was subjected to ring-closing metathesis to give enone $\mathbf{1 6 5}$ in $85 \%$ yield. Isomerization of the freshly prepared $\mathbf{1 6 5}$ to more stable $\alpha, \beta$-unsaturated enone with $\mathrm{RhCl}_{3}$ [79] afforded pavidolide B (166) in $95 \%$ yield.

The synthesis of (-)-conidiogenone B (171) featured a Danheiser's [3 + 2] annulation [74,80] and was reported by Zhai and co-workers in 2020 [73] (Scheme 13C). Treatment of tricycle 167 with allene 168 in the presence of $\mathrm{TiCl}_{4}$ gave the desired 169 carrying two vicinal quaternary carbons. A one-pot desilylation of the newly formed $\mathbf{1 6 9}$ with a trifluoride-acetic acid complex produced the tetraquinane 170a in $89 \%$ yield with a $4: 1 \mathrm{dr}$. The conversion of the freshly prepared ketone $170 \mathrm{a}$ to 170b was achieved in three steps. Ozonolysis of the $\mathrm{C}=\mathrm{C}$ double bond of 170b gave a keto aldehyde (not shown), which was subjected to an acid-mediated aldol reaction to give conidiogenone $\mathrm{B}(\mathbf{1 7 1})$ in $53 \%$ yield. The undesired isomer with $\beta, \gamma$ $\mathrm{C}=\mathrm{C}$ double bond (not shown) was formed in $34 \%$ yield and can be isomerized to the more stable $\alpha, \beta$-unsaturated enone to afford conidiogenone B (171) in 32\% yield upon treatment with $\mathrm{RhCl}_{3}$ in microwave.

The reaction mechanism of Danheiser's [3 +2$]$ annulation is shown according to the Danheiser's proposal [74] (Scheme 13C, inset). Initial complexation of the $\alpha, \beta$-unsaturated ketone $\mathbf{1 6 7}$ and titanium tetrachloride produces an alkyoxy allylic carbocation (not shown). This carbocation is subjected to a regiospecific electrophilic substitution of allene $\mathbf{1 6 8}$ to generate a vinyl cation 172, which is stabilized by an adjacent carbon-silicon bond. The 1,2-shift of the silyl group in $\mathbf{1 7 2}$ produces an isomeric vinyl cation, which is intercepted by the titanium enolate and results in the new $\mathrm{C}-\mathrm{C}$ bond formation to give the five-membered carbocycle $\mathbf{1 6 9}$.

\section{Conclusion}

The all-carbon $[3+2]$ cycloaddition, together with the $[3+2]$ annulation, continue to be an attractive class of reactions for the synthesis of highly-substituted and stereo-congested five-membered carbocycles. Also, one or more quaternary carbons can be created in a single reaction making this class of reactions appealing to complex natural product syntheses. This review outlines the development of the all-carbon [3+2] cycloaddition and its application in natural product synthesis reported from 2011-2020 (inclusive). The intermolecular all-carbon $[3+2]$ cycloaddition offers a facile approach to install functionalized five-carbon carbocycles, including fused-rings (e.g., longeracinphyllin A (10)) and/or spiro-ring (e.g., marcfortine B (8)), at later stage of the synthesis without the need of preinstallation of necessary functional groups as a reaction precursor, for instance, ring-closing metathesis, intramolecular aldol condensation, and others.

One major issue that still needs to be addressed is the selectivity of the all carbon $[3+2]$ cycloadditions, which are usually under substrate-control. Remarkable innovation of the stereoselective palladium-catalyzed trimethylenemethane cycloaddition reported by Trost's group, which makes use of catalytic amounts of palladium and chiral phosphine ligand 74, was applied successfully in the enantioselective synthesis of marcfortine C (9, Scheme 4B). Another brilliant example is the development of a chiral-phosphine-catalyzed [3+2] annulation reported by $\mathrm{Lu}$ in 2019 , in which the chiral phosphine catalyst confers high stereocontrol on the formation of a spiro adduct bearing two vicinal all-carbon quaternary stereocenters (Scheme 7). We believe that the enantioselective all-carbon $[3+2]$ cycloaddition provides a new strategy for the preparation of $\mathrm{sp}^{3}$-carbon-enriched complex scaffolds [81,82] for biological studies and potential new drug development.

The all-carbon [3 + 2] cycloaddition is undoubtedly an efficient synthetic transformation that creates two $\mathrm{C}-\mathrm{C}$ bonds in a single reaction. However, the prior protection of the reactive functional groups, such as the hydroxy and amino groups, are still necessary for most of the all-carbon [3 + 2] cycloaddition reactions. We predict that further development of the all-carbon $[3+2]$ cyclization with the reactive functional groups' compatibilities and/or without the use of protecting groups $[83,84]$ can improve the synthetic efficiency and make this class of reactions more attractive to the synthetic scientist for applications. Lastly, we anticipate that the all-carbon [3 + 2] cycloaddition will gain further attention from the synthetic community, including scientists from academia and pharmaceutical industry, for methodic innovation and the efficient synthesis of biologically important natural products.

\section{Acknowledgements}

The author thanks C. Hui (Max Planck Institute of Molecular Physiology) for helpful discussion during the preparation of this manuscript. The authors would like to thank the anonymous reviewers for their thought-provoking comments and apologize to colleagues whose work was not cited owing to selected coverage. 


\section{Funding}

Financial support from the Shenzhen Human Resources and Social Security Bureau (50820190066) to Z. Wang is gratefully acknowledged. J. Liu acknowledges the financial support from Shenzhen Science and Technology Innovation Committee (grant nos. JCYJ20190809181011411).

\section{ORCID ${ }^{\circledR}$ iDs}

Zhuo Wang - https://orcid.org/0000-0002-4771-2449

\section{References}

1. Hasler, C. M.; Acs, G.; Blumberg, P. M. Cancer Res. 1992, 52, 202-208.

2. Ogbourne, S. M.; Suhrbier, A.; Jones, B.; Cozzi, S.-J.; Boyle, G. M.; Morris, M.; McAlpine, D.; Johns, J.; Scott, T. M.; Sutherland, K. P.; Gardner, J. M.; Le, T. T. T.; Lenarczyk, A.; Aylward, J. H.; Parsons, P. G. Cancer Res. 2004, 64, 2833-2839. doi:10.1158/0008-5472.can-03-2837

3. Aoki, S.; Watanabe, Y.; Sanagawa, M.; Setiawan, A.; Kotoku, N.; Kobayashi, M. J. Am. Chem. Soc. 2006, 128, 3148-3149. doi:10.1021/ja057404h

4. Kiewert, C.; Kumar, V.; Hildmann, O.; Rueda, M.; Hartmann, J.; Naik, R. S.; Klein, J. Brain Res. 2007, 1128, 70-78. doi:10.1016/j.brainres.2006.10.042

5. Kubo, M.; Okada, C.; Huang, J.-M.; Harada, K.; Hioki, H.; Fukuyama, Y. Org. Lett. 2009, 11, 5190-5193. doi:10.1021/ol9021029

6. Ratnayake, R.; Covell, D.; Ransom, T. T.; Gustafson, K. R.; Beutler, J. A. Org. Lett. 2009, 11, 57-60. doi:10.1021/ol802339w

7. Jang, J.-H.; Asami, Y.; Jang, J.-P.; Kim, S.-O.; Moon, D. O.; Shin, K.-S.; Hashizume, D.; Muroi, M.; Saito, T.; Oh, H.; Kim, B. Y.; Osada, H.; Ahn, J. S. J. Am. Chem. Soc. 2011, 133, 6865-6867. doi:10.1021/ja1110688

8. Zeng, X.-P.; Cao, Z.-Y.; Wang, Y.-H.; Zhou, F.; Zhou, J. Chem. Rev. 2016, 116, 7330-7396. doi:10.1021/acs.chemrev.6b00094

9. Li, H.; Lu, Y. Asian J. Org. Chem. 2017, 6, 1130-1145. doi:10.1002/ajoc.201700220

10. Feng, J.; Holmes, M.; Krische, M. J. Chem. Rev. 2017, 117, 12564-12580. doi:10.1021/acs.chemrev.7b00385

11. Li, C.; Ragab, S. S.; Liu, G.; Tang, W. Nat. Prod. Rep. 2020, 37, 276-292. doi:10.1039/c9np00039a

12. Long, R.; Huang, J.; Gong, J.; Yang, Z. Nat. Prod. Rep. 2015, 32 , 1584-1601. doi:10.1039/c5np00046g

13. Huisgen, R. Angew. Chem., Int. Ed. Engl. 1963, 2, 565-598. doi:10.1002/anie.196305651

14. Little, R. D.; Muller, G. W. J. Am. Chem. Soc. 1979, 101, 7129-7130. doi:10.1021/ja00517a086

15. Little, R. D. Chem. Rev. 1986, 86, 875-884. doi:10.1021/cr00075a010

16. Trost, B. M.; Chan, D. M. T. J. Am. Chem. Soc. 1979, 101, 6429-6432. doi:10.1021/ja00515a046

17. Zhang, C.; Lu, X. J. Org. Chem. 1995, 60, 2906-2908. doi:10.1021/jo00114a048

18. Saito, K.; Sogou, H.; Suga, T.; Kusama, H.; Iwasawa, N. J. Am. Chem. Soc. 2011, 133, 689-691. doi:10.1021/ja108586d

19. Lee, H.-Y. Acc. Chem. Res. 2015, 48, 2308-2319. doi:10.1021/acs.accounts.5b00178

20. Ni, H.; Chan, W.-L.; Lu, Y. Chem. Rev. 2018, 118, 9344-9411. doi:10.1021/acs.chemrev.8b00261
21. Trost, B. M.; Mata, G. Acc. Chem. Res. 2020, 53, 1293-1305. doi:10.1021/acs.accounts.0c00152

22. Little, R. D.; Muller, G. W. J. Am. Chem. Soc. 1981, 103, 2744-2749. doi:10.1021/ja00400a043

23. Paquette, L. A.; Sauer, D. R.; Cleary, D. G.; Kinsella, M. A.; Blackwell, C. M.; Anderson, L. G. J. Am. Chem. Soc. 1992, 114, 7375-7387. doi:10.1021/ja00045a007

24. Lee, H.-Y.; Kim, Y. J. Am. Chem. Soc. 2003, 125, 10156-10157. doi:10.1021/ja036263।

25. Wang, J.-C.; Krische, M. J. Angew. Chem., Int. Ed. 2003, 42, 5855-5857. doi:10.1002/anie.200352218

26. Adams, T. E.; El Sous, M.; Hawkins, B. C.; Hirner, S.; Holloway, G.; Khoo, M. L.; Owen, D. J.; Savage, G. P.; Scammells, P. J.; Rizzacasa, M. A. J. Am. Chem. Soc. 2009, 131, 1607-1616. doi:10.1021/ja808402e

27. Trost, B. M.; Chan, D. M. T. J. Am. Chem. Soc. 1983, 105, 2315-2325. doi:10.1021/ja00346a035

28. Berson, J. A.; Duncan, C. D.; Corwin, L. R. J. Am. Chem. Soc. 1974, 96, 6175-6177. doi:10.1021/ja00826a035

29. Kang, T.; Kim, W.-Y.; Yoon, Y.; Kim, B. G.; Lee, H.-Y. J. Am. Chem. Soc. 2011, 133, 18050-18053. doi:10.1021/ja207591e

30. Kang, T.; Song, S. B.; Kim, W.-Y.; Kim, B. G.; Lee, H.-Y. J. Am. Chem. Soc. 2014, 136, 10274-10276. doi:10.1021/ja5054412

31. Lee, H.; Kang, T.; Lee, H.-Y. Angew. Chem., Int. Ed. 2017, 56, 8254-8257. doi:10.1002/anie.201704492

32. Johnson, C. R.; Zeller, J. R. Tetrahedron 1984, 40, 1225-1233. doi:10.1016/s0040-4020(01)82409-1

33. Saksena, A. K.; Mangiaracina, P. Tetrahedron Lett. 1983, 24, 273-276. doi:10.1016/s0040-4039(00)81383-0

34. Lipshutz, B. H.; Parker, D. A.; Kozlowski, J. A.; Nguyen, S. L. Tetrahedron Lett. 1984, 25, 5959-5962. doi:10.1016/s0040-4039(01)81732-9

35. Van Hijfte, L.; Little, R. D.; Petersen, J. L.; Moeller, K. D. J. Org. Chem. 1987, 52, 4647-4661. doi:10.1021/jo00230a001

36. Trost, B. M.; Mignani, S. M.; Nanninga, T. N. J. Am. Chem. Soc. 1986, 108, 6051-6053. doi:10.1021/ja00279a070

37. Greco, G. E.; Gleason, B. L.; Lowery, T. A.; Kier, M. J.; Hollander, L. B.; Gibbs, S. A.; Worthy, A. D. Org. Lett. 2007, 9 , 3817-3820. doi:10.1021/ol7017246

38. Trost, B. M.; Cramer, N.; Bernsmann, H. J. Am. Chem. Soc. 2007, 129 3086-3087. doi:10.1021/ja070142u

39. Trost, B. M.; Bringley, D. A.; Zhang, T.; Cramer, N. J. Am. Chem. Soc. 2013, 135, 16720-16735. doi:10.1021/ja409013m

40. Ohno, M.; Ishizaki, K.; Eguchi, S. J. Org. Chem. 1988, 53, 1285-1288. doi:10.1021/jo00241a030

41. Li, J.; Zhang, W.; Zhang, F.; Chen, Y.; Li, A. J. Am. Chem. Soc. 2017, 139, 14893-14896. doi:10.1021/jacs.7b09186

42. Chen, Y.; Zhang, W.; Ren, L.; Li, J.; Li, A. Angew. Chem., Int. Ed. 2018, 57, 952-956. doi:10.1002/anie.201711482

43. Chen, X.; Zhang, H.-J.; Yang, X.; Lv, H.; Shao, X.; Tao, C.; Wang, H.; Cheng, B.; Li, Y.; Guo, J.; Zhang, J.; Zhai, H. Angew. Chem., Int. Ed. 2018, 57, 947-951. doi:10.1002/anie.201709762

44. Wallace, D. J.; Sidda, R. L.; Reamer, R. A. J. Org. Chem. 2007, 72, 1051-1054. doi:10.1021/jo062170l

45. Hammar, P.; Ghobril, C.; Antheaume, C.; Wagner, A.; Baati, R.; Himo, F. J. Org. Chem. 2010, 75, 4728-4736. doi:10.1021/jo100488g

46. Chan, W.-L.; Tang, X.; Zhang, F.; Quek, G.; Mei, G.-J.; Lu, Y. Angew. Chem., Int. Ed. 2019, 58, 6260-6264. doi:10.1002/anie.201900758 
47. Li, F.-Z.; Li, S.; Zhang, P.-P.; Huang, Z.-H.; Zhang, W.-B.; Gong, J.; Yang, Z. Chem. Commun. 2016, 52, 12426-12429. doi:10.1039/c6cc06794h

48. Overman, L. E.; Paone, D. V. J. Am. Chem. Soc. 2001, 123, 9465-9467. doi:10.1021/ja0166141

49. Long, R.; Huang, J.; Shao, W.; Liu, S.; Lan, Y.; Gong, J.; Yang, Z. Nat. Commun. 2014, 5, 5707. doi:10.1038/ncomms6707

50. Zhao, P.; Incarvito, C. D.; Hartwig, J. F. J. Am. Chem. Soc. 2006, 128, 3124-3125. doi:10.1021/ja058550q

51. Zhao, P.; Incarvito, C. D.; Hartwig, J. F. J. Am. Chem. Soc. 2006, 128, 9642-9643. doi:10.1021/ja063347w

52. Ma, S.; Negishi, E.-i. J. Am. Chem. Soc. 1995, 117, 6345-6357. doi:10.1021/ja00128a025

53. Burns, A. R.; McAllister, G. D.; Shanahan, S. E.; Taylor, R. J. K. Angew. Chem., Int. Ed. 2010, 49, 5574-5577. doi:10.1002/anie.201002416

54. Conia, J. M.; Le Perchec, P. Synthesis 1975, 1-19. doi:10.1055/s-1975-23652

55. Senda, T.; Ogasawara, M.; Hayashi, T. J. Org. Chem. 2001, 66, 6852-6856. doi:10.1021/j00103930

56. Hayashi, T.; Takahashi, M.; Takaya, Y.; Ogasawara, M. J. Am. Chem. Soc. 2002, 124, 5052-5058. doi:10.1021/ja012711i

57. Sun, Z.-M.; Zhao, P. Angew. Chem., Int. Ed. 2009, 48, 6726-6730. doi:10.1002/anie.200901097

58. Zheng, N.; Zhang, L.; Gong, J.; Yang, Z. Org. Lett. 2017, 19, 2921-2924. doi:10.1021/acs.orglett.7b01154

59. Shao, W.; Huang, J.; Guo, K.; Gong, J.; Yang, Z. Org. Lett. 2018, 20 , 1857-1860. doi:10.1021/acs.orglett.8b00380

60. Justik, M. W.; Koser, G. F. Tetrahedron Lett. 2004, 45, 6159-6163. doi:10.1016/j.tetlet.2004.06.029

61. Fernández González, D.; Brand, J. P.; Waser, J. Chem. - Eur. J. 2010, 16, 9457-9461. doi:10.1002/chem.201001539

62. Nomura, K.; Okazaki, K.; Hori, K.; Yoshii, E. J. Am. Chem. Soc. 1987, 109, 3402-3408. doi:10.1021/ja00245a035

63. White, J. D.; Shin, H.; Kim, T.-S.; Cutshall, N. S. J. Am. Chem. Soc. 1997, 119, 2404-2419. doi:10.1021/ja963567h

64. Hou, S.-H.; Tu, Y.-Q.; Liu, L.; Zhang, F.-M.; Wang, S.-H.; Zhang, X.-M. Angew. Chem., Int. Ed. 2013, 52, 11373-11376. doi:10.1002/anie.201306369

65. Luche, J. L. J. Am. Chem. Soc. 1978, 100, 2226-2227. doi:10.1021/ja00475a040

66. Kusama, H.; Ebisawa, M.; Funami, H.; Iwasawa, N. J. Am. Chem. Soc. 2009, 131, 16352-16353. doi:10.1021/ja907633b

67. Jia, X.; Lei, H.; Han, F.; Zhang, T.; Chen, Y.; Xu, Z.; Nakliang, P.; Choi, S.; Guo, Y.; Ye, T. Angew. Chem., Int. Ed. 2020, 59, 12832-12836. doi:10.1002/anie.202005048

68. Zhu, W.; Fang, J.; Liu, Y.; Ren, J.; Wang, Z. Angew. Chem., Int. Ed. 2013, 52, 2032-2037. doi:10.1002/anie.201206484

69. Hullaert, J.; Winne, J. M. Angew. Chem., Int. Ed. 2016, 55 , 13254-13258. doi:10.1002/anie.201606411

70. Zhang, H.; Curran, D. P. J. Am. Chem. Soc. 2011, 133, 10376-10378. doi:10.1021/ja2042854

71. Zhang, P.-P.; Yan, Z.-M.; Li, Y.-H.; Gong, J.-X.; Yang, Z. J. Am. Chem. Soc. 2017, 139, 13989-13992. doi:10.1021/jacs.7b07388

72. Zhang, P.; Li, Y.; Yan, Z.; Gong, J.; Yang, Z. J. Org. Chem. 2019, 84, 15958-15971. doi:10.1021/acs.joc.9b02230

73. Xu, B.; Xun, W.; Su, S.; Zhai, H. Angew. Chem., Int. Ed. 2020, 59, 16475-16479. doi:10.1002/anie.202007247
74. Danheiser, R. L.; Carini, D. J.; Basak, A. J. Am. Chem. Soc. 1981, 103, 1604-1606. doi:10.1021/ja00396a071

75. Miura, K.; Fugami, K.; Oshima, K.; Utimoto, K. Tetrahedron Lett. 1988, 29, 5135-5138. doi:10.1016/s0040-4039(00)80701-7

76. Bhat, V. T.; Duspara, P. A.; Seo, S.; Abu Bakar, N. S. B.; Greaney, M. F. Chem. Commun. 2015, 51, 4383-4385. doi:10.1039/c4cc09987g

77. Fadeyi, O. O.; Mousseau, J. J.; Feng, Y.; Allais, C.; Nuhant, P.; Chen, M. Z.; Pierce, B.; Robinson, R. Org. Lett. 2015, 17, 5756-5759. doi:10.1021/acs.orglett.5b03184

78. Kimura, M.; Fujimatsu, H.; Ezoe, A.; Shibata, K.; Shimizu, M.; Matsumoto, S.; Tamaru, Y. Angew. Chem., Int. Ed. 1999, 38, 397-400 doi:10.1002/(sici)1521-3773(19990201)38:3<397::aid-anie397>3.0.co; $2-y$

79. Schwarz, M.; Graminski, G. F.; Waters, R. M. J. Org. Chem. 1986, 51, 260-263. doi:10.1021/j000352a031

80. Becker, D. A.; Danheiser, R. L. J. Am. Chem. Soc. 1989, 111, 389-391. doi:10.1021/ja00183a071

81. Lovering, F.; Bikker, J.; Humblet, C. J. Med. Chem. 2009, 52, 6752-6756. doi:10.1021/jm901241e

82. Karageorgis, G.; Foley, D. J.; Laraia, L.; Waldmann, H. Nat. Chem. 2020, 12, 227-235. doi:10.1038/s41557-019-0411-x

83. Young, I. S.; Baran, P. S. Nat. Chem. 2009, 1, 193-205. doi:10.1038/nchem.216

84. Hui, C.; Chen, F.; Pu, F.; Xu, J. Nat. Rev. Chem. 2019, 3, 85-107. doi:10.1038/s41570-018-0071-1

\section{License and Terms}

This is an Open Access article under the terms of the Creative Commons Attribution License (https://creativecommons.org/licenses/by/4.0). Please note that the reuse, redistribution and reproduction in particular requires that the author(s) and source are credited and that individual graphics may be subject to special legal provisions.

The license is subject to the Beilstein Journal of Organic Chemistry terms and conditions: (https://www.beilstein-journals.org/bjoc/terms)

The definitive version of this article is the electronic one which can be found at: https://doi.org/10.3762/bjoc.16.251 